\title{
Surface Characterization of Mechanochemically Modified Exfoliated Halloysite Nanoscrolls
}

\section{Authors: Balazs Zsirka, Attila Taborosi, Peter Szabo, Robert K. Szilagyi, Erzsebet Horvath, Tatjana Juzsakova, David Fertig, and Janos Kristof}

This document is the unedited author's version of a Submitted Work that was subsequently accepted for publication in Langmuir, copyright (C) American Chemical Society after peer review. To access the final edited and published work, see https://dx.doi.org/10.1021/ acs.langmuir.6b04606.

Zsirka, Balázs; Táborosi, Attila; Szabó, Péter; Szilagyi, Robert; Horváth, Erzsébet; Juzsakova, Tatjána; Fertig, Dávid; Kristof, Janos. (2017). Surface Characterization of Mechanochemically Modified Exfoliated Halloysite Nanoscrolls. Langmuir. doi: 10.1021/acs.langmuir.6b04606 


\title{
Surface Characterization of Mechanochemically
}

\section{Modified Exfoliated Halloysite Nanoscrolls}

\author{
Balázs Zsirka, ${ }^{a}$ Attila Táborosi, ${ }^{a}$ Péter Szabó, ${ }^{c}$ Róbert K. Szilágyi, ${ }^{b *}$ Erzsébet Horváth, ${ }^{a *}$ \\ Tatjána Juzsakova, ${ }^{a}$ Dávid Fertig, ${ }^{c}$ János Kristóf ${ }^{c}$
}

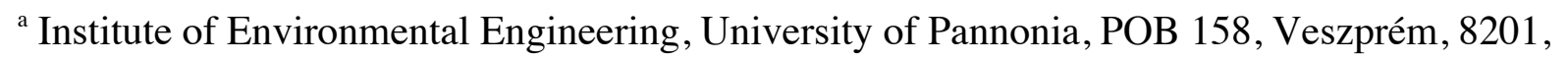
HUNGARY

${ }^{\mathrm{b}}$ Department of Chemistry and Biochemistry, Montana State University, POB 173400 , Bozeman, MT, 59717, U.S.A.

${ }^{\mathrm{c}}$ Department of Analytical Chemistry, University of Pannonia, POB 158, Veszprém, 8201, HUNGARY

\section{Corresponding Authors}

*Authors to whom correspondence should be addressed to: erzsebet.horvath@gmail.com and szilagyi@montana.edu 


\section{Highlights:}

exfoliated halloysite nanoscrolls prepared from crystalline halloysite-10 ;

thermoanalytical (DTG) versus grinding time curves;

pore volume distribution and acid-base character dependence on grinding;

FTIR-ATR characterization of surfaces as a function of grinding time;

atomic-scale structural modeling of dehydration and dehydroxylation;

potential energy surface of proton-transfer and water-desorption.

KEYWORDS: halloysite nanoscrolls, mechanochemical activation, surface characterization, molecular cluster models; density functional theory.

\section{Graphical Table of Contents figure:}

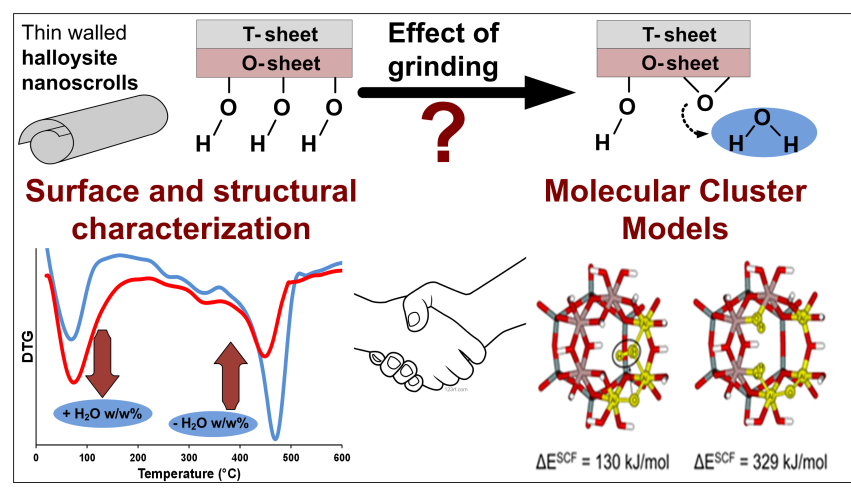




\section{ABSTRACT}

The surface modifications fundamentally influence the morphology of kaolinite nanostructures as a function of crystallinity and presence of contaminants. Beside morphology, the catalytic properties of 1:1-type exfoliated aluminosilicates are also influenced by the presence of defect sites that can be generated in a controlled manner by mechanochemical activation. In this work, we investigated exfoliated halloysite nanoparticles with quasi-homogeneous, scroll-type secondary structure toward developing structure/function relationships for composition, atomic structure, and morphology. The surface properties of thin-walled nanoscrolls were studied as a function of mechanochemical activation expressed by the duration of dry-grinding. The surface characterizations were carried out by $\mathrm{N}_{2}, \mathrm{NH}_{3}$, and $\mathrm{CO}_{2}$ adsorption measurements. The effects of grinding on the nanohalloysite structure were followed by thermoanalytical (TG/DTG) and infrared spectroscopic (FTIR/ATR) techniques. Grinding results in partial dehydroxylation with similar changes as observed for heat treatment above $300{ }^{\circ} \mathrm{C}$. The employed mechanochemical activation shows decrease in dehydroxylation mass loss and the DTG peak temperature, decrease in specific surface area and number of mesopores, increase of surface acidity, blue-shift of surface hydroxide bands, and decrease in intensity in FTIR/ATR bands as a function of grinding time. The experimental observations were used to guide atomic-scale structural and energetic simulations using realistic molecular cluster models for a nanohalloysite particle. A full potential energy surface description was developed for mechanochemical activation and/or heating toward nanometahalloysite formation that aid the interpretation of experimental results. The calculated differences upon dehydroxylation show remarkable agreement with the mass-loss values from DTG measurements. 


\section{INTRODUCTION}

Halloysite, a member of the kaolinite family, is a 1:1 (or TO) type aluminosilicate consisting of Si-centered tetrahedra $(\mathrm{T})$ and Al-centered octahedra (O). Its chemical composition $\left[\mathrm{Al}_{2} \mathrm{Si}_{2} \mathrm{O}_{5}(\mathrm{OH})_{4}\right] \times n \mathrm{H}_{2} \mathrm{O}$ differs in the degree of hydration $(n)$ from that of the kaolinite. In the fully hydrated form $(n=2)$, a sheet of water monolayer is present between the TO-layers that results in increased basal distance $\mathrm{d}(001)$ of $10 \AA$ (halloysite $10 \AA$ form, $\mathbf{H - 1 0 \AA}$ ) relative to the $7.1 \AA$ as in dehydrated halloysite or in kaolinite. The tubular morphology of $\mathbf{H - 1 0 \AA}$ with onedimensional meso- or macroporosity enables a diverse set of applications as catalyst supports, filling or packing materials, or nanoscale chemical reactors. ${ }^{1}$ The $\mathbf{H - 1 0 \AA}$ has a unique morphology that is nanostructured and quasi-homogeneous despite showing all signs of crystallinity. In order to access smaller dimensions for the nanotubes by reduction of crystalline order, intercalation, exchange-intercalation, delamination, exfoliation, mechanochemical activation (dry-grinding), and direct heat treatment methods have been discussed in literature..$^{2-3}$ These surface treatments are effective means to reduce the wall thickness of halloysite nanotube in order to get thin-walled or exfoliated halloysite particles (H0) with average wall thickness of $7.7 \pm 3.5 \AA^{4} .^{4}$

To date, only limited reliable data exist in the literature for the surface and structural properties of exfoliated minerals of the kaolinite group ${ }^{5-11}$ in part due to the vexing morphological variations. Any new insights into the morphological changes accompanying exfoliation provide valuable assistance in mapping out an ill-defined experimental parameter space. This has the potential to define structure and property relationships in a mixture of nano-sized quasihexagonal and scroll-type particles in greatly varying proportion as a function of the preparation pathway. Toward this goal, the structural and surface characterizations of the exfoliated clay 
nanostructures require a combined approach of experimental techniques and theoretical models. Theoretical models describing the origin of morphological features ${ }^{12}$ and computational chemical models have already been successful in complementing the interpretation of FT-IR, Raman, and NMR spectroscopic results. ${ }^{13-16}$

The catalytic properties in connection with the semiconductor-like nature of the kaolinite group also show a close correlation with the morphology. It was reported recently ${ }^{17}$ that the photochemical activity of the kaolinite shows correlation with the TO-layer structure and morphology rather than the previously assumed degree of dispersion of transition metal oxide contaminants and co-minerals. The morphology of the nanoparticles depends on the crystalline order of the raw material, the nature and amounts of contaminants, the preparation pathways, and the method of energy transmission. In addition, the morphology as a secondary structure feature in addition to the primary structure of $\mathrm{O}$ - and $\mathrm{T}$-sheets, degree of presence of a sheet of water molecules in the interlayer space can further influence surface properties. ${ }^{18}$ Thus, it is more reliable to use the exfoliated halloysite nanomaterial consisting of quasi-homogeneous, scrolltype particles for the exploration of correlations among the morphology, composition, and surface properties. It is of practical importance to understand whether the beneficial effects of modifying surface morphology and creating defect sites can be achieved by mechanochemical activation, such as dry-grinding.

The significance of the present study is the detailed experimental characterization of the surface and structural changes of exfoliated, thin-walled halloysite nanoscrolls induced by drygrinding and heat treatment. The experimental observations were translated into atomic-scale description of dehydration and dehydroxylation processes using a realistic, second generation molecular cluster model developed for exfoliated kaolinite nanoparticles. In turn, the modeling 
rationalizes experimental observations in TG/DTG and FTIR measurements. The potential energy description of every significant proton-transfer and dehydroxylation events were obtained by previously calibrated density functional theory calculations. To date, our work provides the first combined experimental and theoretical descriptions for the structural and surface properties of exfoliated halloysite nanoscrolls.

\section{EXPERIMENTAL}

Synthesis of exfoliated, thin-walled halloysite nanoscrolls

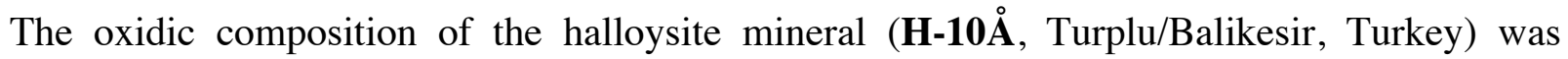
$\mathrm{SiO}_{2}: 46.55, \mathrm{Al}_{2} \mathrm{O}_{3}: 37.10, \mathrm{Fe}_{2} \mathrm{O}_{3}: 0.53, \mathrm{~K}_{2} \mathrm{O}: 0.03, \mathrm{Na}_{2} \mathrm{O}: 0.03, \mathrm{MgO}: 0.23, \mathrm{CaO}: 0.08$ and $\mathrm{TiO}_{2}: 0.04$ (w/w)\%, respectively. The detailed exfoliation procedure for $\mathbf{H - 1 0 \AA}$ is described elsewhere. ${ }^{4,18-19}$ The surface cleaning of the nanomaterial involved the removal of organic matter by washing with IPA and acetone, then with $0.2 \mu \mathrm{S} / \mathrm{cm}$ water in a Soxhlet extractor followed by drying overnight in an oven at $110^{\circ} \mathrm{C}$ and storing it in a desiccator.

\section{Mechanochemical surface activation}

A $200 \mathrm{mg}$ portion of the surface-cleaned exfoliated nanoscroll was ground in a Janetzki KM1 type ball mill (single agate ball, $156.56 \mathrm{~g}$ ) for $0,30,90,120$, and 180 minutes for samples designated as H0, H30, H90, H120, and H180, respectively. 


\section{TG/DTG measurements}

Thermogravimetric experiments were carried out in a Netzsch TG 209-type thermobalance at a heating rate of $5^{\circ} \mathrm{C} / \mathrm{min}$ in nitrogen atmosphere (Messer Griesheim, 99.995\% purity). Ground samples were heated to 200 and $370^{\circ} \mathrm{C}$ for off-line FT-IR analyses. The highly similar sample masses $(6.75 \pm 0.01 \mathrm{mg})$ allowed for direct qualitative and quantitative comparison of the DTG curves. The overlapping features on the DTG curves were resolved by employing the least number of Gaussian+Lorentzian line-shape components $\left(\mathrm{R}^{2}=0.996\right)$ using the Jandel Scientific PeakFit version 4 program.

\section{$\underline{\text { Transmission electron microscopy, porosity, and acid-base character measurements }}$}

Transmission electron microscopic (TEM) images were obtained with a Jeol JEM-1011 type electron microscope at an accelerating voltage of $60 \mathrm{kV}$. The samples were suspended in distilled water before placing on a 300 mesh FORMVAR-coated copper grid.

The specific surface area, pore volume, and pore size distribution in the micropore (1.7-2 nm), mesopore $(2-50 \mathrm{~nm})$, and the macropore $(50-100 \mathrm{~nm})$ diameter ranges were determined by $\mathrm{N}_{2}$ adsorption/desorption isotherms. The measurements were conducted using a Micromeritics ASAP 2000-type instrument on samples (weight $\sim 1 \mathrm{~g}$ ) previously outgassed in vacuum at $160^{\circ} \mathrm{C}$. Pretreatment of each sample was completed as the vacuum dropped below $10 \mu \mathrm{mHg}$. The surface areas of the samples were determined by the BET (Brunauer-Emmett-Teller) method ${ }^{20}$ from the corresponding $\mathrm{N}_{2}$ adsorption isotherm. The pore size distribution and volume values were calculated from the nitrogen desorption isotherms using the BJH (Barret-Joyner-Halenda) model $^{21}$ using Micromeritics ASAP 2000 analysis technique (ASAP 2000 operational program V1.03). 
Changes in surface acidic and basic properties of exfoliated nanoscroll samples (H0-H180) as a function of grinding time were investigated by ammonia (Messer-Griesheim, 99.98\%) and by carbon dioxide (Messer-Griesheim, 99.95\%) pulse chemisorption measured on a PC 2705 Micromeritics instrument at a constant temperature of $30^{\circ} \mathrm{C}$ using He carrier gas. The dynamic flowing gas technique of analysis was employed. The quantity of gas taken up by the sample surface was monitored using a thermal conductivity detector (TCD). Data were used to calculate the amount of adsorbed probe molecule gases $\left(\mu \mathrm{mol} / \mathrm{m}^{2}\right)$. The surface-cleaned sample in an amount of $0.2 \mathrm{~g}$ was put in a $\mathrm{U}$ shape sample holder and kept in helium (Messer-Griesheim, $99.99 \%$ ) flow of $20 \mathrm{ml} / \mathrm{min}$ for $8 \mathrm{~h}$ at $180^{\circ} \mathrm{C}$ before pulse chemisorption. Sorption measurements of $\mathrm{NH}_{3}$ and $\mathrm{CO}_{2}$ probe molecules were used to study acidic and basic sites, respectively, at constant temperature of $30{ }^{\circ} \mathrm{C}$ using He carrier gas with $25 \mathrm{ml} / \mathrm{min}$ flow rate. Probe molecule dose of $1 \mathrm{ml}$ was injected to the sample several times up to total saturation of the sample surface.

\section{FT-IR measurements}

Fourier-transform infrared (FT-IR) spectroscopic measurements were made on a BRUKER Vertex 70 type spectrometer with a Bruker Platinum ATR adapter in nitrogen atmosphere. The spectra were recorded at a resolution of $2 \mathrm{~cm}^{-1}$ with a room temperature DTGS detector by averaging 1024 scans. The interference of atmospheric $\mathrm{H}_{2} \mathrm{O}$ and $\mathrm{CO}_{2}$ was eliminated by flushing the heated and cooled samples with flowing $\mathrm{N}_{2}$ gas in a thermobalance. For off-line FT-IR analysis, ground samples were heated to 200,370 , and $453-472{ }^{\circ} \mathrm{C}$ and measured immediately. 


\section{Computational models and methods}

The molecular cluster model of the exfoliated halloysite nanoparticle (H0) is shown in Figure 1. The model's stoichiometry $\left[\mathrm{Al}_{36} \mathrm{Si}_{36} \mathrm{O}_{198} \mathrm{H}_{144}\right]$ coincidentally corresponds to ideal halloysite stoichiometry of $\left[\mathrm{Al}_{2} \mathrm{O}_{3} \cdot 2 \mathrm{SiO}_{2} \cdot 2 \mathrm{H}_{2} \mathrm{O}\right]$ with additional water molecules in between the halloysite layers $\left(18 \times\left[\mathrm{Al}_{2} \mathrm{O}_{3} \cdot 2 \mathrm{SiO}_{2} \cdot 4 \mathrm{H}_{2} \mathrm{O}\right]\right)$. This model is termed Generation $2(\mathbf{G 2})$, which contains a center honeycomb (red circle in Figure 1) surrounded by 6 outer honeycombs (blue circles in Figure 1) for each Al- and Si-layer. The inner sphere environments of the 7 [6Al-6(HO)] and 7 [6Si-6O] honeycombs are capped by 12 incomplete outer sphere honeycombs (green circles in Figure 1), which places $12 \mathrm{Al}^{3+}$ and $12 \mathrm{Si}^{4+}$ ions at the edges of the model with $\left[\mathrm{Al}(\mathrm{OH})_{4}(\mathrm{O})_{2}\right]$ and $\left[\mathrm{Si}(\mathrm{O})_{4}\right]$ coordination environments, respectively.

Charge neutrality was achieved by protonating the dangling groups at the edges of the G2 model with 24 surface hydroxides (e-sHO- $), 8$ apical oxides $\left(\mathrm{e}-\mathrm{aO}^{2-}\right)$, and 24 bridging oxide (e$\mathrm{bO}^{2-}$ ) groups. We adopted guidelines for proton positions from an experimental work ${ }^{22}$ and a follow up computational study using periodic halloysite models. ${ }^{23}$ The initial protonation turned out to be optimal, since upon structural optimization, only two edge-surface water $\left(\mathrm{e}-\mathrm{sOH}_{2}\right)$ groups converted spontaneously to two edge-inner water $\left(\mathrm{e}-\mathrm{iOH}_{2}\right)$ groups. Furthermore, the G2 model defines 42 surface hydroxide $\left(\mathrm{sHO}^{-}\right)$and 14 inner hydroxide (iHO-) groups for the nonperipheral Al-honeycombs, 22 e-sOH ${ }_{2}, 2$ e-sHO- 2 e-iOH ${ }_{2}, 6$ e-iHO', 8 e-aHO ${ }^{-}$, and 24 e-bHO groups at the edges. The $\mathrm{iHO}^{-}$groups define directionality for the nanoparticle through the slip or misfit (Figure 1) between the O- and T-sheets. Front edge sections have ledges of Al octahedra, while the rear edges contain $\mathrm{Si}$ tetrahedra protrusions. The misfit occurs along the ' $\mathrm{a}$ ' crystallographic axis, while the TO-layer periodicity is along the ' $c$ ' axis. The misfit divides the 
nanohalloysite phases into 5 different peripheral environments as summarized in Figure 1 along with the corresponding Miller indices.

Figures $1 \mathrm{~B}$ and $1 \mathrm{C}$ define the nomenclature used for differentiating among the various $\mathrm{sHO}^{-}$ groups in order to provide unique assignments for proton-transfer pathways and concomitant water-desorption processes. We use the labels $\alpha$ - and $\beta$-s $\mathrm{HO}^{-}$for geminal and vicinal groups, respectively, relative to an $\mathrm{iHO}^{-}$group. The proximal and distal annotations differentiate between hydroxides or oxides pointing inward or outward relative to the centroids of an $\mathrm{Al}$ - or $\mathrm{Si}$ honeycombs defined by surface hydroxide $\left(\mathrm{X}_{\mathrm{sO}}\right.$, Figure $\left.1 \mathrm{~B}\right)$ and bridging oxide $\left(\mathrm{X}_{\mathrm{bO}}\right.$, Figure $\left.1 \mathrm{C}\right)$ positions, respectively.

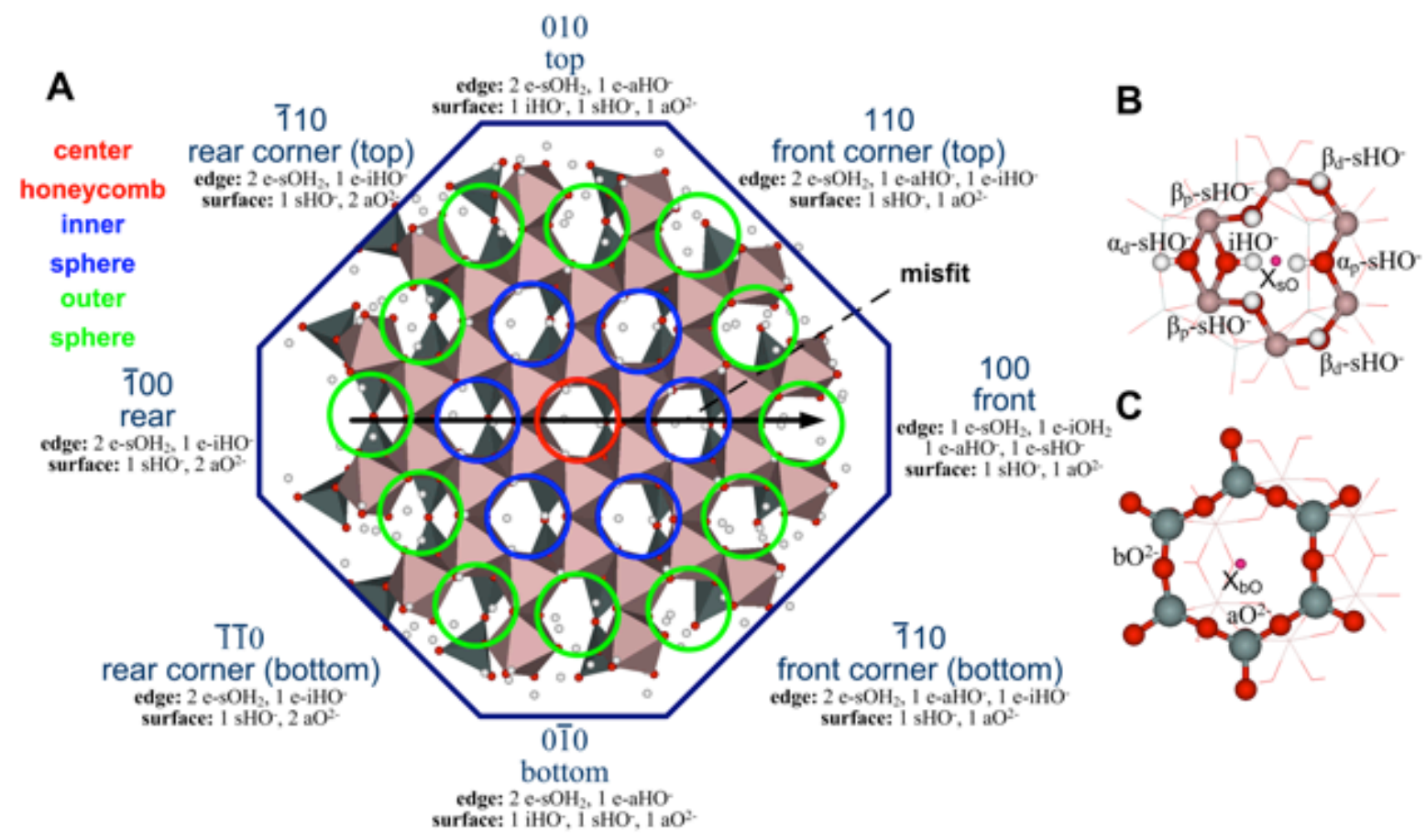

Figure 1. The molecular cluster model (A) used in this study for nanohalloysite (Generation 2, $18 \times\left[\mathrm{Al}_{2} \mathrm{O}_{3} \cdot 2 \mathrm{SiO}_{2} \cdot 4 \mathrm{H}_{2} \mathrm{O}\right]$ stoichiometry, 414 atoms, $2700 \mathrm{e}$ ) with inner sphere (red and blue circles) and outer sphere (green circles) Al- and Si- honeycombs; nomenclature for different types of surface hydroxide groups ( $\mathrm{p}$ : proximal and $\mathrm{d}$ : distal relative to the center of the honeycomb $\left(\mathrm{X}_{\mathrm{sO}} / \mathrm{X}_{\mathrm{bO}}\right), \alpha$ : geminal to and $\beta$ : vicinal position to $\mathrm{iHO}^{-}$groups) for the central (red circle) Al- or Si-honeycomb (B and C panels, respectively). 
For all calculations, we used the PW91+D/SVP/PCM(water) level of theory, which include the PW91 $1^{24-25}$ pure DFT functional with dispersion correction $(+\mathrm{D})^{26}$ and all electron SVP basis set. ${ }^{27-}$ ${ }^{28}$ Each of the 21 computational models considered here were embedded into a water-based $(\varepsilon=78)$ polarizable continuum $\operatorname{model}^{29}(\operatorname{PCM}($ water $))$. All calculations were carried out in the Gaussian09 package. ${ }^{30}$ Visualizations of the molecular structures were done by ChemCraft ${ }^{31}$ and DS ViewerPro ${ }^{32}$ programs. No constraints were applied during structural optimizations with the exception of guided proton-transfer and water-desorption processes for localizing transition states. The stability of the stationary structures was confirmed by repeated restarts in order to avoid being trapped in local minima after shaking all atomic positions by $\pm 0.20 \AA$ random displacements. The proton-transfer pathways were mapped in a relaxed potential energy surface scan. The highest energy point was refined in transition state optimization converging to a single imaginary normal mode.

Experimentally relevant thermodynamic values were estimated from the electronic energy $\left(\Delta \mathrm{E}^{\mathrm{SCF}}\right.$ ) to avoid the prohibitive computational cost of vibrational analysis for a large number of structures that were considered here. The enthalpy and Gibbs free energy corrections were determined for proton-transfer process between an edge-bridging $\mathrm{HO}^{-}$to an edge-apical $\mathrm{HO}^{-}$site $\left(\Delta \mathrm{H}^{\text {corr }}=+3 \mathrm{~kJ} / \mathrm{mol}, \Delta \mathrm{G}^{\text {corr }}=+4 \mathrm{~kJ} / \mathrm{mol}\right)$ and follow up water-desorption from the edge-apical $\mathrm{H}_{2} \mathrm{O}$ site $\left(\Delta \mathrm{H}^{\text {corr }}=-4 \mathrm{~kJ} / \mathrm{mol}, \Delta \mathrm{G}^{\text {corr }}=-60 \mathrm{~kJ} / \mathrm{mol}\right)$. The low values of enthalpy corrections indicate that entropic considerations will be significant for water-desorption $\left(\Delta S^{\text {corr }}=188 \mathrm{~J} / \mathrm{molK}\right.$ at room temperature). As a computational control, a similar full vibrational analysis and thermochemical calculation were also carried out for the dehydroxylation of two adjacent surface hydroxide groups $\left(\Delta \mathrm{H}^{\text {calc }}=+367 \mathrm{~kJ} / \mathrm{mol}, \Delta \mathrm{G}^{\text {calc }}=+316 \mathrm{~kJ} / \mathrm{mol}\right)$, which shows that the estimated values $\left(\Delta \mathrm{H}^{\text {est }}=+375\right.$ $\mathrm{kJ} / \mathrm{mol}, \Delta \mathrm{G}^{\text {est }}=+319 \mathrm{~kJ} / \mathrm{mol}$ from $\Delta \mathrm{E}^{\mathrm{SCF}}=379 \mathrm{~kJ} / \mathrm{mol}$ ) are within $10 \mathrm{~kJ} / \mathrm{mol}$ of the calculated ones. 


\section{RESULTS AND DISCUSSION}

\section{TEM characterization, porosity measurements, and acid-base character of the surfaces}

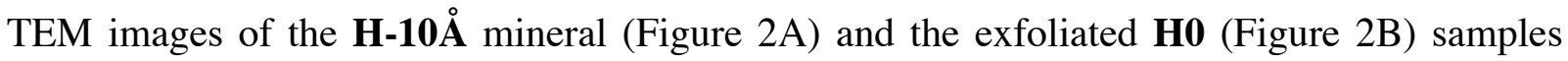
show the characteristic changes in wall thickness ${ }^{4}$ as a result of going from a crystalline starting material with nano-scale dimension (Figure 2A2) in terms of scroll diameter to individual TOlayers with curved up edges or completely rolled up morphology (Figure 2B2). These morphological differences correspond to characteristic differences in specific surface area (SSA), cumulative pore volume (V), and average pore diameter (D) as reported earlier between $\mathbf{H - 1 0 \AA}$ and H0.

Figures $2 \mathrm{C} 1$ and $2 \mathrm{C} 2$ show unambiguously the tremendous morphological changes in exfoliated, thin-walled halloysite nanoparticles as a result of 3 hours of dry-grinding (H180) relative to the untreated $\mathbf{H 0}$ sample (Figures $2 \mathrm{~B} 1$ and 2B2). The mechanochemical activation destroys the tubular morphology; however, not completely as one can recognize small platy halloysite particles in Figure $2 \mathrm{C} 2$ with curled up edges. The water generated during dry-grinding from dehydration and more importantly from dehydroxylation processes act as an agglomerating reagent and stick the particles together into clumps of matter as shown in Figure $2 \mathrm{C} 1$. We can consider the TEM images in Figure 2C panels as a few hundred nm-resolution structure of nanometakaolinite phase with highly activated OT-sheets toward water adsorption and in general acid/base reactivity. This is actually will be probed by gas adsorption experiments below. 


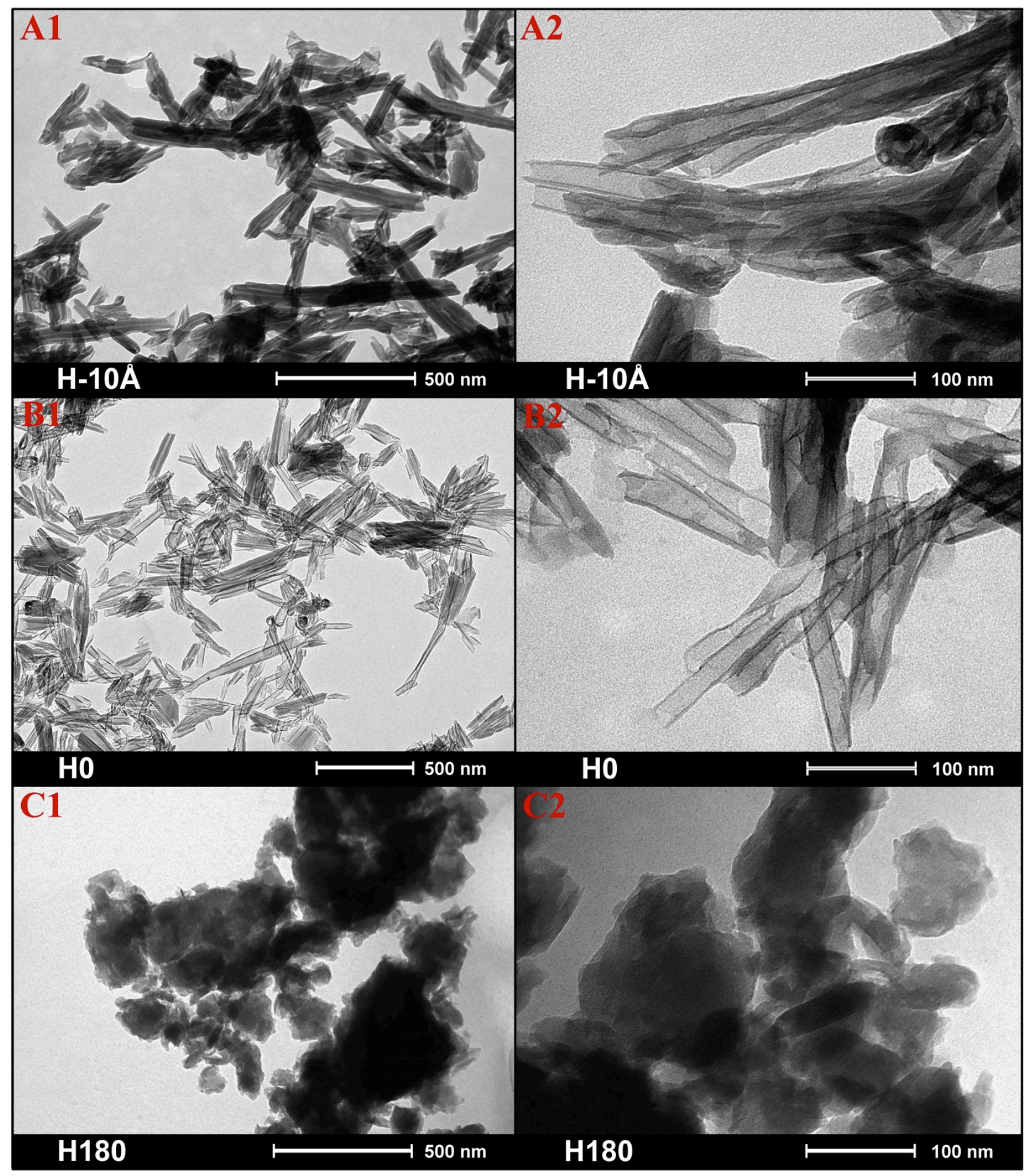

Figure 2. TEM images of (A) untreated halloysite mineral $(\mathbf{H}-10 \AA)$ with thick-wall nanoscrolls and (B) exfoliated, thin-wall halloysite nanoscrolls (H0); (C) mechanochemically activated halloysite nanoscrolls for 3 hours (H180). 
Furthermore, we extended the TEM investigations between crystalline and exfoliated halloysite samples toward changes in the above properties from $\mathrm{N}_{2}$-adsorption measurements as a function of grinding time up to 3 hours. Table 1 shows trends in changes in SSA, V, and D values with increasing mechanochemical activation. The decrease in BET and BJH specific surface areas can be rationalized by amorphization, agglomeration, and meta-nanohalloysite formation. Due to agglomeration, meso- and macro-pores are formed that results in slight variation in the BJH surface area and increase in the pore diameter and volume (Table 1, H180). Based on the $\mathrm{BJH}$ theory, the logarithmic pore volume distribution was calculated from the desorption branch of the $\mathrm{N}_{2}$ adsorption-desorption curves (Figure 3) with a maximum value for H0 at $\sim 20 \mathrm{~nm}$. Upon grinding, the amount of mesopores was drastically reduced and the distribution curve considerably widened $(\mathbf{H 3 0}-\mathbf{H 1 8 0})$. These trends indicate size reduction and partial damage of the nanoscrolls due to mechanochemical activation.

The overall similarity of the SSA, V, and D values for samples H30-H180 in comparison to the starting material HO in Table 1 and the corresponding curves in Figure 3 suggest highly similar behavior of the mechanochemically activated samples in transport processes. However, significant differences were observed in chemical composition and structure, since grinding creates defect sites that influence the acid-base properties of the surface. The results of $\mathrm{NH}_{3}$ and $\mathrm{CO}_{2}$ adsorption experiments (last two columns in Table 1) show the increased population of the acidic surface centers upon grinding interacting with $\mathrm{NH}_{3},{ }^{34}$ while the change is less systematic for the basic centers. The lack of a clear trend in $\mathrm{CO}_{2}$ adsorption can be rationalized by considering the amphoteric behavior of the $\mathrm{sHO}^{-}$groups with respect of acid/base properties. As discussed for the boehmite dehydroxylation forming $\gamma-\mathrm{Al}_{2} \mathrm{O}_{3},{ }^{35-36}$ the $\mathrm{sHO}^{-}$groups manifest acidic properties when they are in bridging position as the two $\mathrm{Al}^{3+}$ sites reduce its $\mathrm{pK}_{\mathrm{a}}$ value. However, 
the end-on coordinated terminal $\mathrm{sHO}^{-}$at an $\mathrm{Al}^{3+}$ site can remain alkaline. Upon mechanical activation, initially the concentration of terminal $\mathrm{sHO}^{-}$increases as indicated by the increased $\mathrm{CO}_{2}$ adsorption (Table 1, last column). Continued grinding rearranges the surface, as more $\mathrm{Al}^{3+}$ becomes coordinatively unsaturated (as can be seen by the increased $\mathrm{NH}_{3}$ adsorption in Table 1) in comparison to the initial sample $\mathbf{H 0}$. The terminal $\mathrm{sHO}^{-}$groups move into bridging positions to stabilize the $\mathrm{Al}^{3+}$ sites and thus reduce the surface alkalinity. The jump in $\mathrm{CO}_{2}$ adsorption after 120 min grinding can be correlated with the accumulation of trapped water formed during dehydroxylation, which the $\mathrm{CO}_{2}$ reacts on the surface to form carbonate. ${ }^{37}$

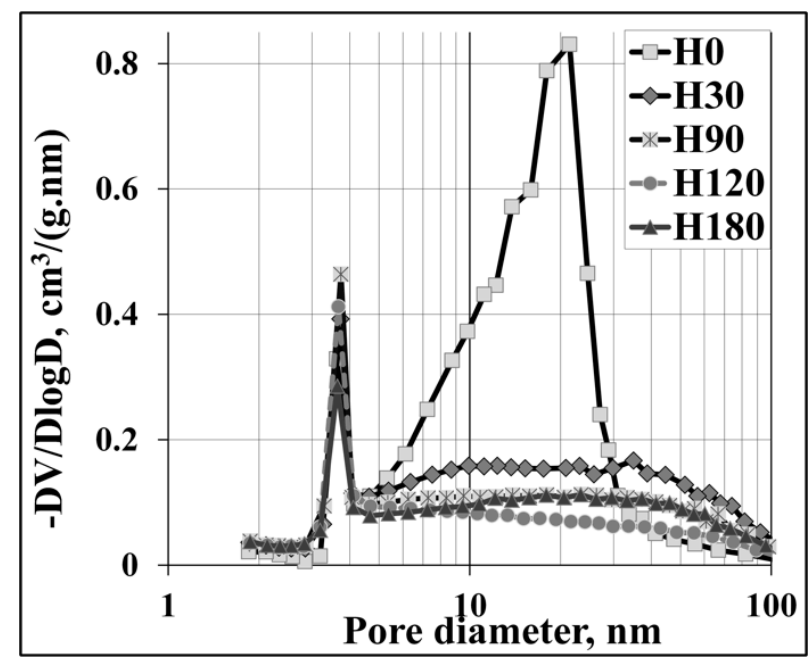

Figure 3. Logarithmic BJH pore volume distribution curves; the $\mathrm{N}_{2}$ adsorption-desorption vs. grinding time curves are provided as supporting information (Figure S1). The peak in the 3-4 nm pore diameter range is methodological error due to capillary condensation. ${ }^{33}$ 
Table 1. Changes of specific surface area (SSA from BET and BJH models), cumulated pore volume $\left(\mathrm{V}_{1.7-300}\right)$, average pore size diameter (D), $\mathrm{NH}_{3}$ and $\mathrm{CO}_{2}$ adsorption as a function of grinding time.

\begin{tabular}{crrrrcc}
\hline $\begin{array}{c}\text { grinding time } \\
(\mathrm{min})\end{array}$ & \multicolumn{2}{c}{$\mathrm{SSA}\left(\mathrm{m}^{2} / \mathrm{g}\right)$} & $\mathrm{V}_{1.7-300}$ & $\begin{array}{c}\mathrm{D} \\
(\mathrm{cm})\end{array}$ & $\begin{array}{c}\mathrm{NH}_{3} \\
\left(\mu \mathrm{mol} / \mathrm{m}^{2}\right)\end{array}$ & $\begin{array}{c}\mathrm{CO}_{2} \\
\left(\mu \mathrm{mol} / \mathrm{m}^{2}\right)\end{array}$ \\
0 & 132 & 145 & 0.3953 & 11.5 & 1.74 & 0.50 \\
30 & 91 & 91 & 0.2173 & 8.5 & 3.22 & 0.70 \\
90 & 83 & 81 & 0.1676 & 7.5 & 3.78 & 0.37 \\
120 & 78 & 73 & 0.1304 & 6.4 & 5.55 & 0.28 \\
180 & 76 & 74 & 0.1560 & 7.6 & 5.56 & 0.64 \\
\hline
\end{tabular}

\section{Thermal analysis}

The TG and DTG curves of the H0-H180 nanoscrolls were recorded as a function of mechanochemical activation. Three dominant regions can be clearly distinguished based on the shapes of the TG/DTG curves in Figure 4. The two largest mass loss steps correspond to processes at low $\left(\sim 70{ }^{\circ} \mathrm{C}\right)$ and high $\left(\sim 460{ }^{\circ} \mathrm{C}\right)$ temperatures as can be seen on the TG curves (Figure 4A). The DTG curves (Figure 4B) show multiple, greatly overlapping processes for the intermediate temperature range that can be assigned to water-desorption; however, their origins are masked by the limitations of this technique.

Characteristic mass loss values (Table 2) were calculated from resolved DTG curves (Figure $\mathrm{S} 3$ ). The weakly bound or adhesive water is lost up to $183 \pm 18{ }^{\circ} \mathrm{C}$ during the first step from the surface. The second step is a drawn out procedure of multiple water-desorption events in strongly overlapping processes up to $369 \pm 10 \quad{ }^{\circ} \mathrm{C}$. The third step corresponds to the dehydroxylation process with DTG peak maxima in the range of $450-469{ }^{\circ} \mathrm{C}$. In the latter step, both the DTG peak area and peak temperature decrease with increasing grinding time. This means that the magnitude of mass loss and the strength of chemical interactions are reduced associated with water-desorption and dehydroxylation, respectively. In parallel, the DTG peak area corresponding to the first step increases as mechanochemical activation increases the 
amount of adhesive surface water. The diminishing dehydroxylation step for sample $\mathbf{H 1 8 0}$ suggests the formation of a significant amount of nanometahalloysite that may contribute to the lack of clear trends in both the thermal analysis, porosity, $\mathrm{NH}_{3} / \mathrm{CO}_{2}$ adsorption measurements. The overall mass loss values (last column in Table 2) increase with grinding time, since the destabilization of nanohalloysite particles increases their reactivity upon grinding.

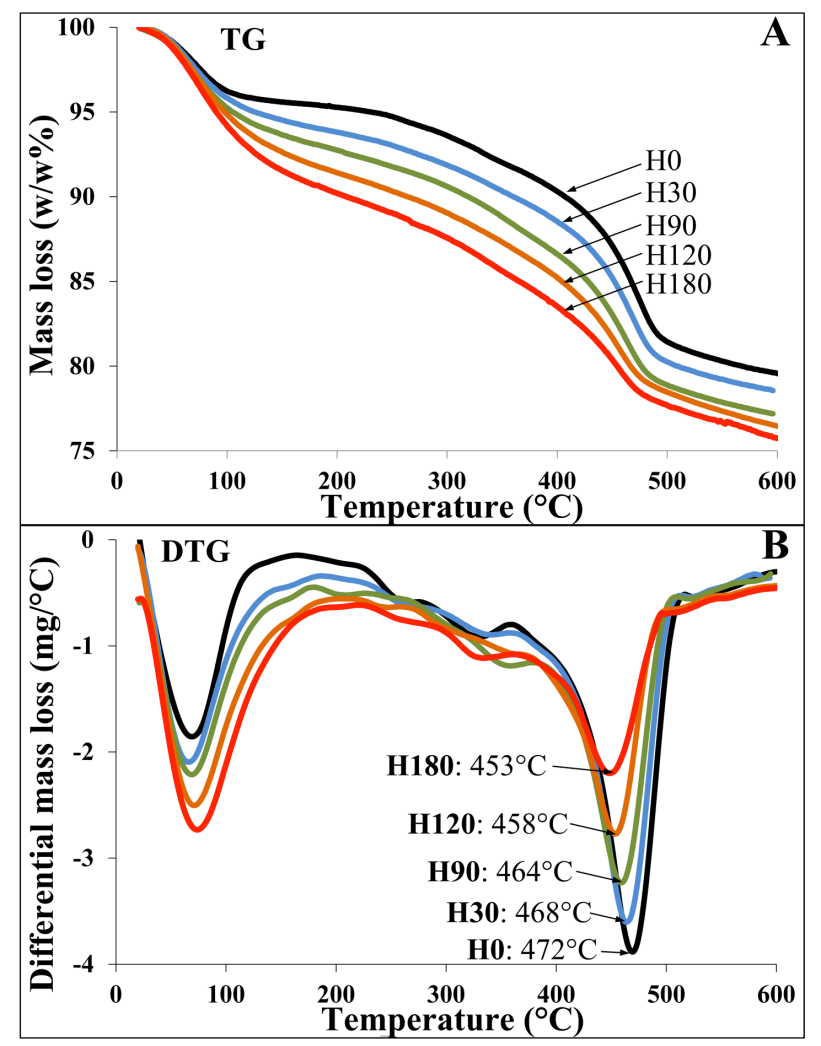

Figure 4. Thermogravimetric (A) and derivative thermogravimetric (B) curves for exfoliated halloysite nanoscrolls as a function of grinding time. The resolved DTG curves are shown in Figure S2.

During dry-grinding, the local temperature at the particles surface can reach the dehydroxylation range..$^{34}$ This can result in the conversion of surface and inner hydroxide groups of the Al-centered octahedra to form the so-called "structural water" ${ }^{38}$ In addition, the formation 
of the activated surface leads to the increased amount of adhesive water as can be concluded from the increased DTG peak area for the first dehydration step. Throughout grinding, the peaks corresponding to the intermediate temperature region show a significant overlap (see Figure S3 resolved DTG curves for samples H90-H180). In order to provide a plausible explanation for the presence of various chemical environment, the interactions of hydroxides via proton-transfer events, and desorption of weakly or strongly bound water, and the overall atomic-scale events occurring at each major mass loss step were further investigated using molecular cluster models (see below).

Table 2. Mass loss in (w/w) \% of nanohalloysite as a function of grinding time: dehydration (Step 1: $\Delta \mathrm{T}_{1}=20-183 \pm 18{ }^{\circ} \mathrm{C}$ ), overlapping dehydration and dehydroxylation (Step 2: $\Delta \mathrm{T}_{2}=183 \pm 18-$ $369 \pm 10{ }^{\circ} \mathrm{C}$ ) and dehydroxylation (Step 3: $\Delta \mathrm{T}_{3}=369 \pm 10{ }^{\circ} \mathrm{C}-600{ }^{\circ} \mathrm{C}$ ) events calculated from the deconvoluted DTG curve (Figure S2).

\begin{tabular}{ccccc}
\hline samples & $\begin{array}{c}\Delta \mathrm{T}_{1} \\
\text { Step 1 }\end{array}$ & $\begin{array}{c}\Delta \mathrm{T}_{2} \\
\text { Step 2 }\end{array}$ & $\begin{array}{c}\Delta \mathrm{T}_{3} \\
\text { Step 3 }\end{array}$ & $\begin{array}{c}\text { total } \\
\text { mass loss }\end{array}$ \\
\hline H0 & 5.1 & 4.1 & 12.2 & 21.4 \\
H90 & 7.6 & 5.8 & 10.4 & 23.8 \\
H120 & 9.3 & 5.1 & 10.0 & 24.4 \\
H180 & 10.2 & 5.5 & 9.3 & 25.0 \\
\hline
\end{tabular}

\section{FT-IR spectroscopic measurements}

The FT-IR spectra of the exfoliated halloysite samples were recorded immediately after being heat-treated at the approximate dehydration and dehydroxylation temperatures $\left(370{ }^{\circ} \mathrm{C}\right)$ as functions of the grinding time. Figure 5 shows that samples H0-H180 manifest significant band shifts and changes in the band ratios in the spectral ranges of the $\mathrm{OH}$ stretching (3700-3600 $\left.\mathrm{cm}^{-1}\right)$, the apical Si/O $\left(\sim 1125 \mathrm{~cm}^{-1}\right)$, the in-plane Si/O/Si $\left(1035-1044,1000-1008 \mathrm{~cm}^{-1}\right)$, the OH deformation (910-904 $\left.\mathrm{cm}^{-1}\right)$, and the $\mathrm{Al} / \mathrm{O} / \mathrm{Si}$ deformation bands $\left(537-520 \mathrm{~cm}^{-1}\right)$. 
In contrast to the crystalline phase, the $\mathrm{sHO}^{-}$groups do not have a uniform direction in the exfoliated particles. ${ }^{14}$ They are involved in a network of weak interactions of varying strengths as a function of nano-scale surface morphologies. These result in overlapping and diffuse bands including two well-separated bands at 3696 and $3626 \mathrm{~cm}^{-1}$ that are assigned to non-bonding $\mathrm{OH}$ $\left(\mathrm{sHO}^{-}\right)$and $\mathrm{iHO}^{-}$stretching modes, respectively. ${ }^{39-41}$ Dehydration and dehydroxylation processes induced by heating decrease the relative intensity of the $3626 \mathrm{~cm}^{-1}$ band along with the decrease of the $\mathrm{sHO}^{-}$stretching bands. The FT-IR spectra of samples heated up to the dehydroxylation onset temperature $\left(370{ }^{\circ} \mathrm{C}\right.$ from Figure $4 \mathrm{~A}$ and also Figure S3) show that the intensity of the $\mathrm{OH}$ stretching bands decreases with the duration of grinding (Figure 5, red lines). While the assignment of bands in the stretching vibration range becomes challenging with increased heating and grinding times, identification of the hydroxide deformation bands is still possible (see e.g. Figure 5, H180). On heating and grinding, the hydroxide deformation bands shift to higher wavenumbers approaching the position of the $\mathrm{iHO}^{-}$bands in kaolinites $\left(916-911 \mathrm{~cm}^{-1}\right) .^{39-}$ 42

In order to rationalize the changes in the characteristic $\mathrm{OH}$ bands of the exfoliated nanoscroll samples, the positions of these groups relative to each other and to the crystallographic 'ab'plane of the TO-layer need to be taken into account. Interpretation of the spectral changes is aided by recent computational chemical results ${ }^{14-15,43}$ for exfoliated kaolinites using both periodic and molecular cluster models and validated level of theory. According to these calculations, one of the three $\mathrm{sHO}^{-}$groups on the Al-centered octahedron folds in to adopt a parallel arrangement with respect to the TO-plane, while the other two have vertical, erected positions as in the crystalline sample. An opposite orientation is also possible at $+10 \mathrm{~kJ} / \mathrm{mol}^{14}$ with two parallel and one perpendicular hydroxide orientations. The adsorbents (e.g. water as studied) on the surface 
can influence the position of the $\mathrm{sHO}^{-}$groups relative to the TO-plane and lift the parallel $\mathrm{OH}$ groups out of the plane. This displacement influences the deformation coordinate of the $\mathrm{iHO}^{-}$ group. In spite that the calculations made for a clean, isolated surface did not take into account inhomogeneity of the surface, presence of contaminants, and chemical speciation of various sites, they aid remarkably well the interpretation of the IR bands.

Since the nanoscroll surface was exposed to continuous He gas purging while being heated in the $370-450{ }^{\circ} \mathrm{C}$ range, there is no significant amount of adsorbed water present during the FTIR measurements. Thus, the molecular cluster model rather well represents the experimentally studied surface. The $\mathrm{sHO}^{-}$groups located at an angle to the TO-plane form H-bonding/ion-dipole interactions with the external chemical environment. The folded-in $\mathrm{sHO}^{-}$groups (also labeled as $\alpha_{\mathrm{p}}-\mathrm{sHO}^{-}$) above the $\mathrm{iHO}^{-}$groups are parallel with the TO-plane and thus show similarity to the $\mathrm{iHO}^{-}$groups. However, their $\mathrm{H}-\mathrm{O}$ bond dipoles point to opposite directions. Therefore, the decreased intensity of the $3626 \mathrm{~cm}^{-1}$ band for the heated (clean) surface is due to the decreased $\mathrm{sHO}^{-}$group coverage of the surface and their increasing tendency to adopt a parallel position with the TO-layer.

Furthermore, grinding and direct heating result in changes in band ratios and shifting of the peak maxima to higher wavenumbers in the in-plane $\mathrm{Si} / \mathrm{O} / \mathrm{Si}$ vibration range (1035-1044, 1000$\left.1008 \mathrm{~cm}^{-1}\right)$ as well. In addition, the band of the $\mathrm{Al} / \mathrm{O} / \mathrm{Si}$ vibration $\left(537-520 \mathrm{~cm}^{-1}\right)$ also shifts to higher wavenumbers as a result of heating and grinding, indicating a reduction in the $\mathrm{Al}$ coordination number, which can influence the in-plane $\mathrm{Si} / \mathrm{O} / \mathrm{Si}$ vibration as well, since the TOlayers are not rigid structures. 


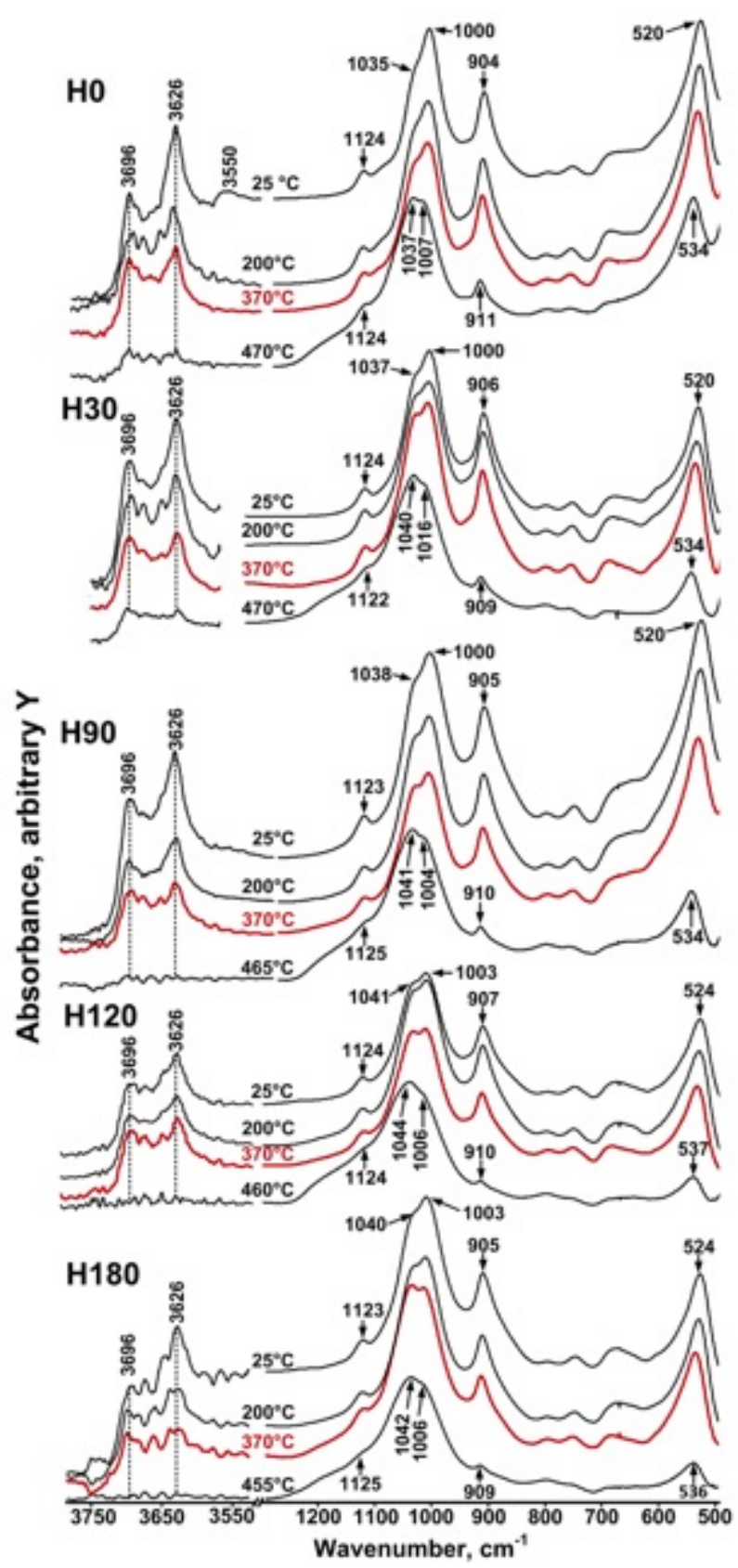

Figure 5. FT-IR spectra of mechanochemically activated samples for various grinding times (H0-H180) as a function of temperature $\left(25-455^{\circ} \mathrm{C}\right)$. The hydroxide stretching region is magnified by $10 x$ (for comparison, only the $370^{\circ} \mathrm{C}$ spectra are shown in Figure S3). 


\section{Systematic atomic-scale modeling of dehydration and dehydroxylation steps}

In order to provide a comprehensive, atomic-scale picture for the independent experimental observations, non-periodic molecular cluster models were employed to map out pathways connecting a diverse set of locations for dehydration and dehydroxylation processes. As will be discussed below, these are not random processes. First, we briefly present the modeling results for water-desorption from the surface and the edges of a halloysite nanoparticle. This is followed by a more detailed analysis of the important proton-transfer and the overall dehydroxylation steps for the surface and inner hydroxides.

\section{Dehydration steps}

Surface. The stepwise desorption of water molecules from the nanoparticle surface was simulated by studying a ring of six water molecules that maximize the number of H-bonding interactions between the water molecules and the central Al-and Si-honeycombs (Figure S4). The average water/O-sheet distance is $2.70 \pm 0.08 \AA$ in the initial structure as defined by

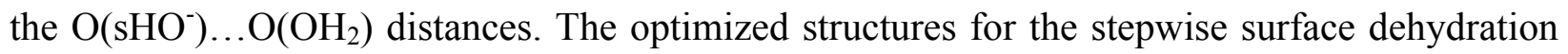
of the O-sheet were obtained by removing the outermost or weakest bound water molecule (Figure S4A, highlighted water molecule). The average stepwise water-desorption energy of an O-sheet bound water molecule for the entire surface dehydration is $\Delta \mathrm{E}^{\mathrm{SCF}}=109 \pm 7 \mathrm{~kJ} / \mathrm{mol}$. On the other hand, the characteristic $\mathrm{bO}^{2-} \ldots \mathrm{O}\left(\mathrm{OH}_{2}\right)$ distances at the T-sheet is $2.89 \pm 0.05 \AA$ and the desorption energy is $\Delta \mathrm{E}^{\mathrm{SCF}}=75 \pm 19 \mathrm{~kJ} / \mathrm{mol}$, respectively. The optimized structures for the partially solvated T-sheet are shown in Figure S4B. There are some variations in the stepwise desorption energies, but there is no clear trend from this limited sampling of possible structures. Previous molecular dynamics and Monte Carlo simulations provide a finer picture for the dehydration process. ${ }^{44-45}$ 
Edges. The coordinated water molecules at the edges of the $\mathbf{G 2}$ model can be considered as representative examples for chemisorbed water due to their direct interaction with the $\mathrm{Al}^{3+}$ and $\mathrm{Si}^{4+}$ ions. The edge water molecules $\left(\mathrm{e}-\mathrm{OH}_{2}\right)$ are present due to charge neutrality; however, proton exchange between the solvent and the nanoparticle solute can also contribute to their formation. The most common edge-coordinated water $\left(22 \mathrm{e}-\mathrm{sOH}_{2}\right.$, in G2) is due to the protonation of surface hydroxides. Contrary to the surface dehydration steps, there are considerable energetic differences depending on the particular edge environment. Figure S5 summarizes three key chemical environments and resulting structural relaxations upon waterdesorption. A common theme for the e- $\mathrm{SOH}_{2}$ desorption is a dramatic rearrangement of a transient five-coordinate $\mathrm{Al}$ site. The lowest energy process (Figure S5A, $\Delta \mathrm{E}^{\mathrm{SCF}}=106 \mathrm{~kJ} / \mathrm{mol}$ ) corresponds to dissociation of a terminal e- $\mathrm{sOH}_{2}$ from a $\left[\mathrm{Al}(\mathrm{sHO})(\mathrm{iHO})(\mathrm{aO})(\mathrm{e}-\mathrm{aOH})\left(\mathrm{e}-\mathrm{sOH}_{2}\right)_{2}\right]^{2-}$ site that is only interacting with the external (solvent) chemical environment. The five-coordinate Al site has an increased Lewis acidity compared to the six-coordinate, which triggers spontaneous proton-transfers. This rearranges the $\mathrm{Al}$ coordination environment to adopt trigonal bipyramidal or square pyramidal geometry. As we move from the outside of the $\mathbf{G} \mathbf{2}$ particle toward the inside, the water is desorbed from a more buried site with more extensive network of interactions. As a consequence, the water desorption energy increases to $155 \mathrm{~kJ} / \mathrm{mol}$ (Figure S5C). However, this higher energy processes likely not be experimentally relevant, because adjacent terminal water molecules will dissociate at lower energy (106 or $139 \mathrm{~kJ} / \mathrm{mol}$ ) upon spontaneous proton-transfers. The trends in water-desorption energies continue as other buried e$\mathrm{iOH}_{2}$ molecules are considered, where the desorption energy is the highest $(175 \mathrm{~kJ} / \mathrm{mol})$ without stabilization of a five-coordinate intermediate via a proton-transfer. 
Chlatrate water. We considered models to describe the 'strongly bound', 'structural', or 'zeolite' water $^{32}$ anchored inside a TO-layer. Their importance is evident from the mass loss values in the intermediate temperature range $\left(183 \pm 18-369 \pm 10{ }^{\circ} \mathrm{C}\right)$ from TG measurements is about $4-6 \%$ for nanohalloysite (Table 2), which is practically absent for nanokaolinite. ${ }^{38}$ Thus, we carried out a systematic mapping for the location of a water molecule by inserting it into Al- and Sihoneycombs and stabilizing through H-bonding. Among six and three possible locations in the Al- and Si-honeycombs (Figure S6, top panels), respectively, we localized only two stationary structures. The Al-honeycomb bound water forms two $\mathrm{H}$-bonds with $\mathrm{aO}^{2-}$ groups, while the $\mathrm{iHO}^{-}$ and the $\alpha_{\mathrm{p}} \mathrm{SHO}^{-}$groups anchor it from the directions of $\mathrm{T}$ - and O-sheets (Figure $\mathrm{S} 6 \mathrm{~A}$ ), respectively. The binding energy of this water $\left(\Delta \mathrm{E}^{\mathrm{SCF}}=-157 \mathrm{~kJ} / \mathrm{mol}\right)$ indicates that this water is held in place under considerable strain. We hypothesize that even if this chlatrate water can be formed during dehydroxylation process (see later), its lifetime likely be short. However, we also localized a water molecule trapped next to the surface of the Si-honeycomb (Figure S6B) by Hbonds from the $\mathrm{iHO}^{-}$group and two vicinal $\mathrm{bO}^{2-}$ groups. The binding energy is now positive $\left(\Delta \mathrm{E}^{\mathrm{SCF}}=53 \mathrm{~kJ} / \mathrm{mol}\right)$, which indicates the likeliness of trapping water closer to the $\mathrm{T}$-sheet than seen for the adhesive water in the bottom right corner of Figure S4B for the last step of T-sheet dehydration $\left(\Delta \mathrm{E}^{\mathrm{SCF}}=61 \mathrm{~kJ} / \mathrm{mol}\right)$. Due to the openness of the Si-honeycomb, this water can be formed even potentially during sample hydration without dehydroxylation taking place. The small binding energy despite the triple H-bonding interaction can be rationalized by the strain imposed on the water molecule being inside a tight Si-honeycomb pocket that renders the dehydration energy less than half of that calculated for the surface adsorbed water. While we have not yet studied in detail, but it is plausible that during dehydroxylation, as the number of Odefect sites increases the strain within the Si-honeycombs reduces, which can facilitate the 
accumulation of chlatrate water and its desorption by temperature that is evidenced in part by the middle temperature range of the TG curves in Figure 4.

\section{Dehydroxylation steps}

A dehydroxylation step is described by the cumulative effects of a proton-transfer between two hydroxide groups and concomitant desorption of the product water molecule. This process leaves behind an $\mathrm{O}^{2-}$ group and forms O-defect site. The desorbing water can leave the surface or stay trapped in the honeycomb pores. In some cases, the proton-transfer results in a stable intermediate at an endothermic level that is comparable in magnitude to dehydration steps, but much lower than the overall dehydroxylation step including water-desorption. Thus, during nanoparticle heating or mechanochemical activation we can anticipate the tautomerism occurs simultaneously and in parallel to dehydration steps. Given the greater importance of the dehydroxylation steps in clay nanoparticle surface activation in comparison to the dehydration processes, we provide a detailed account of the most likely processes to take place that parallel the experimental observations considering an approximately $2 \mathrm{~nm}$, defect-free, kaolinite nanoparticle model.

Edges. Trivially, the lowest energy dehydroxylation step corresponds to the proton-transfer between two adjacent e- $\mathrm{aHO}^{-}$groups generating an $\mathrm{e}-\mathrm{aO}^{2-}$ group and an $\mathrm{e}-\mathrm{aOH}_{2}$ molecule (in short: e- $\mathrm{aHO}^{-} \rightarrow \mathrm{e}-\mathrm{aO}^{2-} / \mathrm{e}-\mathrm{aHO}^{-} \rightarrow \mathrm{e}-\mathrm{aOH}_{2}$ ) without a stationary proton-transfer step. Upon e-aOH desorption at $\Delta \mathrm{E}^{\mathrm{SCF}}=117 \mathrm{~kJ} / \mathrm{mol}$, a large-scale tautomeric rearrangement was observed (right hand side of Figure S7A) similar to edge dehydration processes. However, this process is of limited importance to mass loss due to its single occurrence (Figure 1). 
A more dominant dehydroxylation process for 12 sites is the proton-transfer from an e-bHO- to e-aHO-/e-iHO- positions (e-bHO $\rightarrow$ e- $\mathrm{bO}^{2-} / \mathrm{e}-\mathrm{aHO}^{-} \rightarrow \mathrm{e}^{-} \mathrm{aOH}_{2}$ ), which form stable intermediates at only $\Delta \mathrm{E}^{\mathrm{SCF}}=10 \mathrm{~kJ} / \mathrm{mol}$ (left hand side of Figure S7B) followed by a large-scale rearrangement of the $\mathrm{Al}$ coordination environment upon e-aOH 2 desorption at $\Delta \mathrm{E}^{\mathrm{SCF}}=126 \mathrm{~kJ} / \mathrm{mol}$ (right hand side of Figure S7B). This dominant edge dehydroxylation process was chosen to estimate the entropic $\left(\Delta S_{\mathrm{rxn}}^{0}=188 \mathrm{~J} / \mathrm{mol} \mathrm{K}\right)$ and enthalpic $\left(\Delta H_{\mathrm{rxn}}^{0}=122 \mathrm{~kJ} / \mathrm{mol}\right)$ corrections. Notably, these values give a cross-over temperature of $377{ }^{\circ} \mathrm{C}$ for the dehydroxylation process, which qualitatively agrees with the on-set temperature $\left(\sim 370{ }^{\circ} \mathrm{C}\right)$ of dehydroxylation steps (see above, Figure 4 , Figure S2, and Table 2). As a general trend, the five-coordinate Al-site tends to adopt a coordination environment $\left[\mathrm{Al}(\mathrm{aO})(\mathrm{sHO})(\mathrm{e}-\mathrm{sHO})(\mathrm{e}-\mathrm{iHO})\left(\mathrm{e}-\mathrm{sOH}_{2}\right)\right]^{2-}$ with balanced O-group protonation states.

Additional dehydroxylation steps may take place in 2 positions (Figure 1) for the e-s $\mathrm{HO}^{-} \rightarrow \mathrm{e}-$ $\mathrm{sO}^{2-} / \mathrm{s}-\mathrm{HO}^{-} \rightarrow \mathrm{s}-\mathrm{OH}_{2}\left(\Delta \mathrm{E}^{\mathrm{SCF}}=181 \mathrm{~kJ} / \mathrm{mol}\right)$ and $\mathrm{e}-\mathrm{iHO} \rightarrow \mathrm{e}-\mathrm{iO}^{2-} / \mathrm{e}-\mathrm{bHO}^{-} \rightarrow \mathrm{e}-\mathrm{bOH}_{2}\left(\Delta \mathrm{E}^{\mathrm{SCF}}=237\right.$ $\mathrm{kJ} / \mathrm{mol}$ ) processes at higher energies than the dominant value for edge dehydroxylation. As we move away from the edge region of the nanoparticle $\left(\mathrm{e}-\mathrm{aHO} \rightarrow \mathrm{e}-\mathrm{aO}{ }^{2-} / \mathrm{sHO}^{-} \rightarrow \mathrm{sOH}_{2}\right)$ and consider tautomers of surface hydroxides, the energetic cost of dehydroxylation jumps $\left(\Delta \mathrm{E}_{\mathrm{SCF}}=271\right.$ $\mathrm{kJ} / \mathrm{mol})$ despite the presence of low energy $\left(\Delta \mathrm{E}^{\mathrm{SCF}}=78 \mathrm{~kJ} / \mathrm{mol}\right)$ proton-transfer processes. An even higher energy dehydroxylation step $\left(\Delta \mathrm{E}^{\mathrm{SCF}}=354 \mathrm{~kJ} / \mathrm{mol}\right)$ involves the formation of a threecoordinate $\mathrm{Si}^{4+}$ ion upon the $\mathrm{bOH}_{2}$ dissociation, which is eliminated spontaneously by the formation of a five-membered [5Si-5O] truncated honeycomb at the periphery of the nanoparticle. 
Table 3. Donor/accepter $\mathrm{O}$ atom distances (top) and proton-transfer energies (middle), and complete dehydroxylation energies including the water-desorption (bottom) between the various hydroxide groups of the central Al-honeycomb (red circle in Figure 1; '-' indicates non-existent intermediate; 'n/a' - not possible proton-transfer due to large distance separation)

\begin{tabular}{|c|c|c|c|c|c|}
\hline & $\begin{array}{l}\mathrm{iHO}^{-} \\
\rightarrow \mathrm{iOH}_{2}\end{array}$ & $\begin{array}{l}\alpha_{\mathrm{p}-\mathrm{SHO}^{-}} \\
\rightarrow \alpha_{\mathrm{p}}-\mathrm{s} \mathrm{OH}_{2}\end{array}$ & $\begin{array}{l}\beta_{\mathrm{p}^{-}} \mathrm{SHO}^{-} \\
\rightarrow \beta_{\mathrm{p}^{-}} \mathrm{SOH}_{2}\end{array}$ & $\begin{array}{l}\alpha_{\mathrm{d}^{-}}-\mathrm{SHO}^{-} \\
\rightarrow \alpha_{\mathrm{d}^{-}} \mathrm{SOH} \mathrm{H}_{2}\end{array}$ & $\begin{array}{l}\beta_{\mathrm{d}-} \mathrm{SHO}^{-} \\
\rightarrow \beta_{\mathrm{d}^{-}} \mathrm{SOH} \mathrm{H}_{2}\end{array}$ \\
\hline \multicolumn{6}{|c|}{ donor/acceptor $\mathrm{O}$ atom distances, $\AA$} \\
\hline $\mathrm{iHO}^{-} \rightarrow \mathrm{iO}^{2-}$ & 0 & 4.20 & 2.76 & 2.50 & 4.94 \\
\hline$\alpha_{\mathrm{p}}-\mathrm{sHO}^{-} \rightarrow \alpha_{\mathrm{p}}-\mathrm{sO}^{2-}$ & 4.20 & 0 & 3.05 & 4.97 & 2.78 \\
\hline$\beta_{\mathrm{p}}-\mathrm{SHO}^{-} \rightarrow \beta_{\mathrm{p}^{-}} \mathrm{SO}^{2-}$ & 2.76 & 3.05 & $3.05^{\mathrm{a}}$ & 2.81 & 2.76 \\
\hline$\alpha_{d^{-}}-\mathrm{SHO}^{-} \rightarrow \alpha_{d^{-}} \mathrm{sO}^{2-}$ & 2.50 & 4.97 & 2.81 & 0 & 5.56 \\
\hline$\beta_{\mathrm{d}^{-}} \mathrm{SHO}^{-} \rightarrow \beta_{\mathrm{d}^{-}} \mathrm{SO}^{2-}$ & 4.94 & 2.78 & 2.76 & 5.56 & 0 \\
\hline \multicolumn{6}{|c|}{ proton-transfer only, $\mathrm{kJ} / \mathrm{mol}$} \\
\hline $\mathrm{iHO}^{-} \rightarrow \mathrm{iO}^{2-}$ & - & 175 & 167 & 154 & $\mathrm{n} / \mathrm{a}$ \\
\hline$\alpha_{\mathrm{p}}-\mathrm{SHO}^{-} \rightarrow \alpha_{\mathrm{p}}-\mathrm{sO}^{2-}$ & 175 & - & - & 150 & - \\
\hline 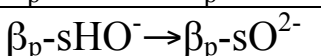 & - & - & - & 138 & - \\
\hline$\alpha_{d^{-}}-\mathrm{SHO}^{-} \rightarrow \alpha_{d^{-}}-\mathrm{SO}^{2-}$ & 131 & $\mathrm{n} / \mathrm{a}$ & 122 & - & $\mathrm{n} / \mathrm{a}$ \\
\hline 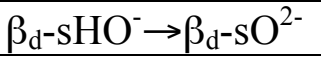 & $\mathrm{n} / \mathrm{a}$ & 130 & 180 & $\mathrm{n} / \mathrm{a}$ & - \\
\hline \multicolumn{6}{|c|}{ dehydroxylation $=$ proton-transfer + water-desorption $\Delta \mathrm{E}^{\mathrm{SCF}}, \mathrm{kJ} / \mathrm{mol}$} \\
\hline $\mathrm{iHO}^{-} \rightarrow \mathrm{iO}^{2-}$ & - & 392 & 361 & 293 & $\mathrm{n} / \mathrm{a}$ \\
\hline$\alpha_{p}-\mathrm{SHO}^{-} \rightarrow \alpha_{\mathrm{p}}-\mathrm{sO}^{2-}$ & 358 & - & 375 & 350 & 330 \\
\hline$\beta_{\mathrm{p}^{-}} \mathrm{sHO}^{-} \rightarrow \beta_{\mathrm{p}^{-}} \mathrm{sO}^{2-}$ & 320 & 339 & 379 & 331 & 319 \\
\hline 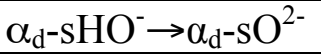 & 301 & $\mathrm{n} / \mathrm{a}$ & 317 & - & $\mathrm{n} / \mathrm{a}$ \\
\hline 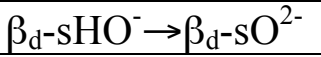 & $\mathrm{n} / \mathrm{a}$ & 329 & 370 & $\mathrm{n} / \mathrm{a}$ & - \\
\hline
\end{tabular}

Surface. Given the number of $\mathrm{sHO}^{-}$and $\mathrm{iHO}^{-}$groups, surface dehydroxylation contributes dominantly to the mass loss observed in TG/DTG (Figure 4 and Table 2). In order to identify all relevant channels for proton-transfer and water-desorption steps, we distinguished among proximal/distal and $\alpha$ - and $\beta$-positions (see Computational Section and Figure 1) for the $\mathrm{sHO}^{-}$ groups. Table 3 summarizes the 16 different pathways for proton-transfer and concomitant water-desorption steps. The rows of Table 3 represent formation of various oxide sites, while the columns correspond to the formation of O-defect sites at the position of inner (i), proximal$\alpha-\left(\alpha_{p}\right)$, proximal- $\beta-\left(\beta_{p}\right)$, distal- $\alpha-\left(\alpha_{d}\right)$, or distal- $\beta-\left(\alpha_{p}\right)$ surface hydroxides. 
There are energetically degenerate proton-transfer processes $\left(\alpha_{\mathrm{d}}-\mathrm{sHO}^{-} \rightarrow \alpha_{\mathrm{d}^{-}}-\mathrm{sO}^{2-} / \beta_{\mathrm{p}}-\mathrm{sHO}^{-} \rightarrow\right.$ $\beta_{\mathrm{p}}-\mathrm{sOH}_{2}, \beta_{\mathrm{d}^{-}}-\mathrm{sHO}^{-} \rightarrow \beta_{\mathrm{d}^{-}}-\mathrm{sO}^{2-} / \alpha_{\mathrm{p}}-\mathrm{sHO}^{-} \rightarrow \alpha_{\mathrm{p}}-\mathrm{sOH}_{2}$, and $\alpha_{\mathrm{d}^{-}}-\mathrm{sHO}^{-} \rightarrow \alpha_{\mathrm{d}}-\mathrm{sO}^{2-} / \mathrm{iHO}^{-} \rightarrow \mathrm{iOH}_{2}$ at 122,130, and $131 \mathrm{~kJ} / \mathrm{mol}$, respectively) followed by blocks of energetically less favored steps, such as the formation of the $\alpha_{\mathrm{d}^{-}} \mathrm{sOH}_{2}$ from either $\alpha_{\mathrm{p}}-\mathrm{sHO}^{-}(150 \mathrm{~kJ} / \mathrm{mol})$ or $\mathrm{iHO}^{-}(154 \mathrm{~kJ} / \mathrm{mol})$. The presence or absence of proton-transfer intermediates can be correlated with the slip or misfit between the O- and T-sheets and asymmetry in the honeycomb composition and geometry (see Figure 1). These affect the reversibility of proton-transfers as can be seen from the different upper-right and lower-left corners of the proton-transfer energy section of Table 3. Similarly to edge dehydroxylation steps, the energetic order of proton-transfers does not correspond to the order of water-desorption. In addition, similarity in forward and reverse processes is also irregular. Each proton-transfer or water-desorption step has its own structural and energetic uniqueness. In the following discussion, we briefly analyze the lowest energy, most important dehydroxylation processes and related structural changes. The entire spectrum of possibilities is provided as supporting information (Table S1).

Inner hydroxide ( $\left.\mathrm{iHO}^{-}\right)$. The $\mathrm{iHO}^{-}$and $\alpha_{\mathrm{d}^{-}} \mathrm{sHO}^{-}$groups are located the closest to each other at $2.50 \AA$. . Despite the shortest O...O distance (top of Table 3), the proton-transfer intermediate is stable at $154 \mathrm{~kJ} / \mathrm{mol}$ due to a supporting network of $\mathrm{H}$-bonding interactions for $\mathrm{iHO}^{-} \rightarrow \mathrm{iO}^{2-} /$ $\alpha_{d}-\mathrm{sHO}^{-} \rightarrow \alpha_{\mathrm{d}}-\mathrm{sOH}_{2}$. The water-desorption step is only $139 \mathrm{~kJ} / \mathrm{mol}$ higher. Top panel in Figure 6A shows minimal structural changes upon dehydroxylation. The Al...Al distance within the central Al-honeycomb increases from $2.88 \AA$ to $3.23 \AA$, despite the greatly reduced $\mathrm{Al}-\mathrm{O}\left(\mathrm{iO}^{2-}\right)$ distance $(1.72 \AA)$ relative to the $\mathrm{Al}-\mathrm{O}(\mathrm{iOH})$ distance of $1.93 \AA$. The electrostatic repulsion between the two $\mathrm{Al}^{3+}$ ions cannot be fully compensated by a single bridging $\mathrm{iO}^{2-}$-group even if it has a double negative charge. 


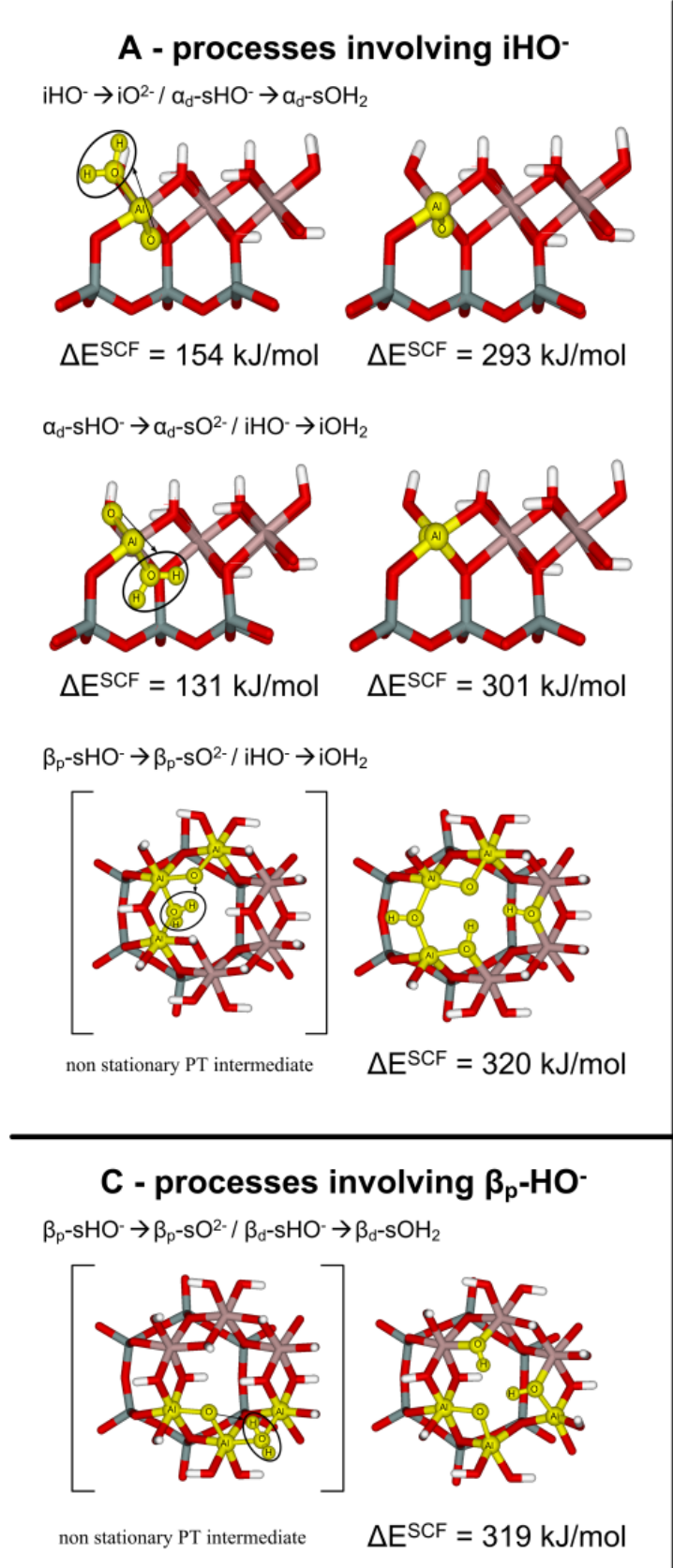

B - processes involving $\alpha_{\mathrm{p}}-\mathrm{HO}^{-}$

$\beta_{\mathrm{d}}-\mathrm{SHO} \rightarrow \beta_{\mathrm{d}}-\mathrm{SO} \mathrm{O}^{2-} / \alpha_{\mathrm{p}}-\mathrm{SHO} \rightarrow \alpha_{\mathrm{p}}-\mathrm{SOH}_{2}$
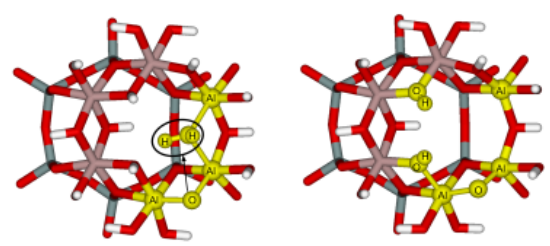

$\Delta \mathrm{E}^{\mathrm{SCF}}=130 \mathrm{~kJ} / \mathrm{mol} \quad \Delta \mathrm{E}^{\mathrm{SCF}}=329 \mathrm{~kJ} / \mathrm{mol}$

$\alpha_{p}-\mathrm{SHO}^{-} \rightarrow \alpha_{\mathrm{p}}-\mathrm{SO} \mathrm{O}^{2-1} / \beta_{\mathrm{d}}-\mathrm{sHO} \rightarrow \beta_{\mathrm{d}}-\mathrm{SOH}_{2}$
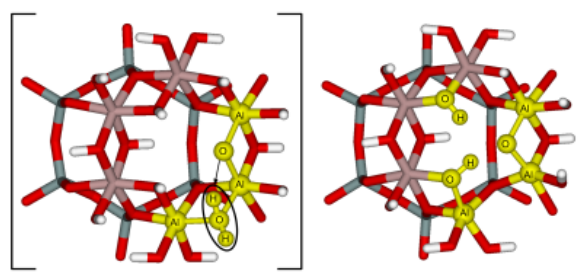

non stationary PT intermediate $\quad \Delta \mathrm{E}^{\mathrm{SCF}}=330 \mathrm{~kJ} / \mathrm{mol}$

\section{D - processes involving $\alpha_{d}-\mathrm{HO}^{-}$}

$a_{d}-\mathrm{SHO} \rightarrow a_{d}-\mathrm{SO}^{2-} / \beta_{\mathrm{p}}-\mathrm{SHO} \rightarrow \beta_{\mathrm{p}}-\mathrm{SOH}_{2}$
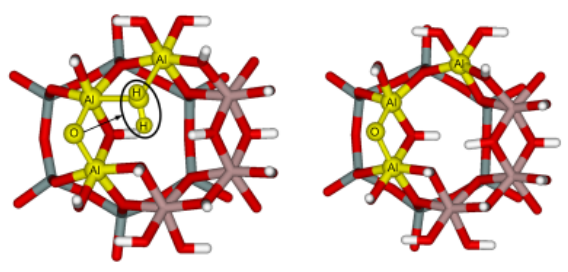

$\Delta \mathrm{E}^{\mathrm{SCF}}=129 \mathrm{~kJ} / \mathrm{mol}$

$\Delta \mathrm{E}^{\mathrm{SCF}}=340 \mathrm{~kJ} / \mathrm{mol}$

$\beta_{p}-\mathrm{SHO} \rightarrow \beta_{\mathrm{p}}-\mathrm{SO}-2-\alpha_{d}-\mathrm{SHO} \rightarrow \alpha_{d}-\mathrm{SOH}_{2}$
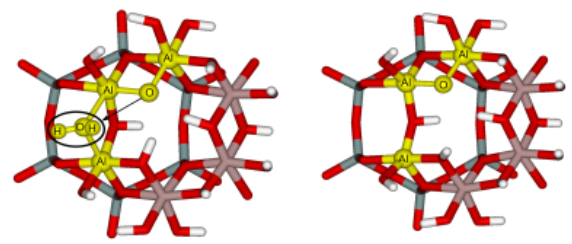

$\Delta \mathrm{E}^{\mathrm{SCF}}=156 \mathrm{~kJ} / \mathrm{mol} \quad \Delta \mathrm{E}^{\mathrm{SCF}}=347 \mathrm{~kJ} / \mathrm{mol}$

Figure 6. Overview of surface hydroxide dehydroxylation steps (proton-transfer: left hand side, water-desorption: right hand side of each panel)

The reverse dehydroxylation process $\alpha_{d}-\mathrm{sHO}^{-} \rightarrow \alpha_{\mathrm{d}^{-}} \mathrm{SO}^{2-} / \mathrm{iHO}^{-} \rightarrow \mathrm{iOH}_{2}$ is only $8 \mathrm{~kJ} / \mathrm{mol}$ higher, despite that the stable proton-transfer intermediate is $24 \mathrm{~kJ} / \mathrm{mol}$ more stable. The extra stability comes from the extensive network of $\mathrm{H}$-bonding interactions with adjacent $\mathrm{aO}^{2-}$ and $\mathrm{bO}^{2-}$ groups 
in the latter. The water desorbs from the interfacial region between the $\mathrm{O}$ - and $\mathrm{T}$-sheets through the Si-honeycomb (middle panel of Figure 6A). Alternatively, this water can be trapped and form a chlatrate water as described above (Figure S6). The Al...Al distance increases to $3.37 \AA$ relative to the reverse process due to the difference in the position of the $\mathrm{sO}^{2-}$ versus the $\mathrm{iO}^{2-}$ groups relative to the center plane of the TO-layer.

The next lowest energy dehydroxylation process is $\beta_{\mathrm{p}}-\mathrm{sHO} \rightarrow \beta_{\mathrm{p}}-\mathrm{sO}^{2-} / \mathrm{iHO}^{-} \rightarrow \mathrm{iOH}_{2}$ (bottom panel of Figure 6A) at $320 \mathrm{~kJ} / \mathrm{mol}$ without a stable proton-transfer intermediate. The greater endothermicity correlates with a larger scale structural rearrangement. Upon the $\mathrm{iOH}_{2}$ waterdesorption, the structure and composition of two adjacent [2Al]-rhombs change, which also involve a conformational change of the other $\beta_{\mathrm{p}}-\mathrm{sHO}^{-}$group from an erected to a folded position (right hand side of the bottom panel in Figure 6A). The $\mathrm{sO}^{2-}$ group is stabilized by two H-bonded $\mathrm{sHO}^{-}$groups. The differences in the erected and folded $\mathrm{sHO}^{-}$groups can be experimentally followed through changes in the $\mathrm{H}-\mathrm{O}$ stretching regions (see Figure 5). The anionic $\alpha_{d^{-}} \mathrm{sHO}^{-}$group holding the two $\mathrm{Al}$ sites together maintains an $\mathrm{Al}$...Al distance of $3.34 \AA$; however, the $\mathrm{Al}-\mathrm{O}$ $\left(\alpha_{\mathrm{d}^{-}} \mathrm{sHO}^{-}\right)$distance is shortened by $0.04 \AA$ relative to initial value of $1.89 \AA$. The H-bonded $\mathrm{sO}^{2-} \ldots \beta_{\mathrm{p}}$-sHO- groups provide an additional anchor for keeping the $\mathrm{Al}$ honeycomb intact.

The reverse process of $\mathrm{iHO}^{-} \rightarrow \mathrm{iO}^{2-} / \beta_{\mathrm{p}}-\mathrm{sHO}^{-} \rightarrow \beta_{\mathrm{p}}-\mathrm{sOH}_{2}$ has a stable proton-transfer intermediate $\left(\Delta \mathrm{E}^{\mathrm{SCF}}=167 \mathrm{~kJ} / \mathrm{mol}\right)$ due to adjacent $\mathrm{H}$-bonding partner from the other $\beta_{\mathrm{p}^{-}}$sHO- group; however, the entire dehydroxylation process is $40 \mathrm{~kJ} / \mathrm{mol}$ higher $\left(\Delta \mathrm{E}^{\mathrm{SCF}}=361 \mathrm{~kJ} / \mathrm{mol}\right)$. The reversible proton-transfer processes in $\alpha_{\mathrm{p}}-\mathrm{sHO}^{-} \rightarrow \alpha_{\mathrm{p}}-\mathrm{sO}^{2-} / \mathrm{iHO}^{-} \rightarrow \mathrm{iOH}_{2}$ and $\mathrm{iHO}^{-} \rightarrow \mathrm{iO}^{2-} / \alpha_{\mathrm{p}}-\mathrm{sHO}^{-} \rightarrow \alpha_{\mathrm{p}}-\mathrm{sOH}_{2}$ at $175 \mathrm{~kJ} / \mathrm{mol}$ correspond to dehydroxylation processes of $\Delta \mathrm{E}^{\mathrm{SCF}}=358$ and $392 \mathrm{~kJ} / \mathrm{mol}$, respectively. The $34 \mathrm{~kJ} / \mathrm{mol}$ difference in dehydroxylation can be explained by the formation of strong surface $\mathrm{H}$-bonding interactions in the former and the lack of any stabilizing interaction in the latter. 
Proximal- $\alpha$-surface hydroxide $\left(\alpha_{\mathrm{p}}\right.$-sHO- $)$. We identified reversible dehydroxylation steps involving $\alpha_{\mathrm{p}}-\mathrm{sHO}^{-}$and adjacent $\beta_{\mathrm{d}^{-}} \mathrm{sHO}^{-}\left(\Delta \mathrm{E}^{\mathrm{SCF}}=329\right.$ and $\left.330 \mathrm{~kJ} / \mathrm{mol}\right)$. However, protontransfer gives a stable intermediate only for $\beta_{\mathrm{d}}-\mathrm{sHO}^{-} \rightarrow \beta_{\mathrm{d}}-\mathrm{sO}^{2-} / \alpha_{\mathrm{p}}-\mathrm{sHO}^{-} \rightarrow \alpha_{\mathrm{p}}-\mathrm{sOH}_{2}$ at $130 \mathrm{~kJ} / \mathrm{mol}$ due to the formation of $\mathrm{H}$-bonded network with the $\beta_{\mathrm{p}}$-sHO group as shown in left hand side of the top panel in Figure 6B. For the $\alpha_{\mathrm{p}}-\mathrm{sHO}^{-} \rightarrow \alpha_{\mathrm{p}}-\mathrm{sO}^{2-} / \beta_{\mathrm{d}}-\mathrm{sHO} \rightarrow \beta_{\mathrm{d}}-\mathrm{sOH}_{2}$ process H-bonding network cannot be formed (left hand side of bottom panel in Figure 6B) within the central (red circle in Figure 1) or an adjacent honeycomb (blue circles in Figure 1). Upon dehydroxylation, a new type of $[2 \mathrm{Al}]$ rhomb is formed with two oxide groups $\left(\mathrm{aO}^{2-}\right.$ and $\left.\mathrm{sO}^{2-}\right)$ with a considerably reduced $\mathrm{Al}$...Al distance $(2.74 \AA$ vs. $2.92 \AA)$, while the overall honeycomb structure remains intact. In the reverse process (right hand side of bottom panel in Figure 6B), the Al...Al distance further shortens to $2.68 \AA$, since the $\mu^{2}-\mathrm{iHO}^{-}$binds the $\mathrm{Al}$ ions tighter than the $\mu^{3}-\mathrm{aO}^{2-}$.

The concerted proton-transfer and water-desorption was found to be only $9-10 \mathrm{~kJ} / \mathrm{mol}$ higher than the above discussed processes for the $\beta_{\mathrm{p}}-\mathrm{sHO}^{-} \rightarrow \beta_{\mathrm{p}}-\mathrm{sO}^{2-} / \alpha_{\mathrm{p}}-\mathrm{sHO}^{-} \rightarrow \alpha_{\mathrm{p}}-\mathrm{sOH}_{2}\left(\Delta \mathrm{E}^{\mathrm{SCF}}=339\right.$ $\mathrm{kJ} / \mathrm{mol}$ ) The reverse process is energetically unfavorable by additional $36 \mathrm{~kJ} / \mathrm{mol}$ due to structural rearrangements affecting $4 \mathrm{Al}$ centers or 3 neighboring [2Al] rhombs. None of them shows a stable proton-transfer intermediate. A less likely dehydroxylation process is when the proton jumps from $\alpha_{\mathrm{p}}$-sHO- to $\alpha_{\mathrm{d}^{-}} \mathrm{sHO}^{-}$connecting the opposite side of an Al-honeycomb $\left(\Delta \mathrm{E}^{\mathrm{SCF}}\right.$ $=350 \mathrm{~kJ} / \mathrm{mol})$. The proton-transfer intermediate is remarkably stable $\left(\Delta \mathrm{E}^{\mathrm{SCF}}=150 \mathrm{~kJ} / \mathrm{mol}\right)$ due to a gated process, since the adjacent $\beta_{\mathrm{p}}-\mathrm{sHO}^{-}$groups fold in, stabilize the $\alpha_{\mathrm{p}}$-s $\mathrm{S}^{2-}$ group, and hinder the reverse proton-transfer.

Proximal- $\beta$-surface hydroxide $\left(\beta_{\mathrm{p}}-\mathrm{sHO}\right)$. We found only a single low energy dehydroxylation process for the $\beta_{\mathrm{p}}-\mathrm{sHO}^{-}\left(\Delta \mathrm{E}^{\mathrm{SCF}}=319 \mathrm{~kJ} / \mathrm{mol}\right)$ without a stable proton-transfer intermediate. Figure $6 \mathrm{C}$ shows a highly similar scenario to bottom panels in either Figures 5A or 5B, where the 
$\beta_{\mathrm{p}}-\mathrm{sO}^{2-}$ group becomes stabilized by two $\mathrm{H}$-bonds. The reverse process of $\beta_{\mathrm{d}}-\mathrm{sHO}^{-} \rightarrow \beta_{\mathrm{d}}-\mathrm{sO}^{2-}$ $\beta_{\mathrm{p}}-\mathrm{sHO}^{-} \rightarrow \beta_{\mathrm{p}}-\mathrm{sOH}_{2}$ results in a stable proton-transfer intermediate $\left(\Delta \mathrm{E}^{\mathrm{SCF}}=180 \mathrm{~kJ} / \mathrm{mol}\right)$ due to the symbiotic effect of $\mathrm{H}$-bonding interactions from an adjacent Al-honeycomb. This is analogous to the processes described in Figure 6B. However, the dehydroxylation process has one of the highest energy values $\left(\Delta \mathrm{E}^{\mathrm{SCF}}=370 \mathrm{~kJ} / \mathrm{mol}\right)$ that is second to the highest energy process to the $\mathrm{iHO}^{-} \rightarrow \mathrm{iO}^{2-} / \alpha_{\mathrm{p}}-\mathrm{sHO}^{-} \rightarrow \alpha_{\mathrm{p}}-\mathrm{sOH}_{2}$ conversion due to involvement of $4 \mathrm{Al}$ ions or 3 [2Al] rhombs versus all of the [2Al] rhombs. The most endothermic dehydroxylation step $\left(\Delta \mathrm{E}^{\mathrm{SCF}}=379 \mathrm{~kJ} / \mathrm{mol}\right)$ involves only the $\beta_{\mathrm{p}}-\mathrm{sHO}^{-}$group in the $\beta_{\mathrm{p}}-\mathrm{sHO}^{-} \rightarrow \beta_{\mathrm{p}}-\mathrm{sO}^{2-} / \beta_{\mathrm{p}}-\mathrm{sHO} \rightarrow$ $\beta_{\mathrm{p}}$-sOH${ }_{2}$ process without a stable proton-transfer intermediate.

Distal surface hydroxides $\left(\alpha_{\mathrm{d}}-\mathrm{sHO}-\right)$. Since the $\beta_{\mathrm{d}^{-}}-\mathrm{sHO}^{-}$has already been discussed, we only considered here the $\alpha_{\mathrm{d}^{-}} \mathrm{sHO}^{-}$group. We found similarities in the proton-transfer process $\alpha_{\mathrm{d}^{-}}-\mathrm{sHO}^{-}$ $\rightarrow \alpha_{\mathrm{d}^{-}}-\mathrm{sO}^{2-} / \beta_{\mathrm{p}}-\mathrm{sHO}^{-} \rightarrow \beta_{\mathrm{p}}-\mathrm{sOH}_{2}$ to the previously discussed $\beta_{\mathrm{d}}-\mathrm{sHO}^{-} \rightarrow \beta_{\mathrm{d}}-\mathrm{sO}^{2-} / \alpha_{\mathrm{p}}-\mathrm{sHO}^{-} \rightarrow \alpha_{\mathrm{p}}-\mathrm{sOH}_{2}$ with respect of structural changes (compare Figures 7C and top panel of 7B) and energetics (122 vs. $130 \mathrm{~kJ} / \mathrm{mol}$ for proton-transfer). The proton-transfer intermediate is stable due to $\mathrm{H}$ bonding from the adjacent $\beta_{\mathrm{p}}-\mathrm{sHO}^{-}$group. The intermediate energy range for the dehydroxylation process $(317 \mathrm{~kJ} / \mathrm{mol})$ or the reverse process of $\beta_{\mathrm{p}}-\mathrm{sHO} \rightarrow \beta_{\mathrm{p}}-\mathrm{sO}^{2-} / \alpha_{\mathrm{d}}$-sHO $\rightarrow$ $\alpha_{\mathrm{d}}-\mathrm{sOH}_{2}(331 \mathrm{~kJ} / \mathrm{mol})$ follows the previously described trends, since in this process $3 \mathrm{Al}$ sites are affected simultaneously. The proton-transfer for the latter process is about $16 \mathrm{~kJ} / \mathrm{mol}$ higher due to protonating a $[2 \mathrm{Al}]$ rhomb with an $\mathrm{iHO}^{-}$versus $\mathrm{an} \mathrm{aO}^{2-}$ in the former.

\section{Kinetic considerations of dehydration, proton-transfer, and dehydroxylation processes}

For the sake of a representative description of dehydroxylation and proton-transfer processes, we carried out transition state analysis for the energetically worst-case scenario of $\mathrm{iHO}^{-} \rightarrow \mathrm{iO}^{2-}$ 
$\alpha_{\mathrm{p}}-\mathrm{sHO}^{-} \rightarrow \alpha_{\mathrm{p}}-\mathrm{sOH}_{2}$ with proton-transfer and water-desorption energies of 175 and $392 \mathrm{~kJ} / \mathrm{mol}$ (Table 3), respectively. The transition state structure was refined from the maximum of relaxed potential energy surface scans (Figure 7, blue trace). The scan revealed a rather spectacular pliability of the Al-honeycomb. As the $\mathrm{H}\left(\mathrm{iHO}^{-}\right)$approaches the $\mathrm{O}\left(\alpha_{\mathrm{p}}-\mathrm{sHO}^{-}\right)$, both hydroxides move considerably closer to each other and pinch together the opposite sides of the Alhoneycomb. The displacements of the $\mathrm{O}$ atoms toward each other are astonishing 0.80 and 0.87 $\AA$, respectively, relative to their initial positions in the stationary G2 structure. Transition state optimization refined this structure to $\Delta \mathrm{E}^{\mathrm{SCF}}=244 \mathrm{~kJ} / \mathrm{mol}$ with $-510 \mathrm{~cm}^{-1}$ imaginary normal mode (see inset in Figure 7) and $\mathrm{O} . . . \mathrm{H}\left(\mathrm{iHO}^{-}\right)$and $\mathrm{H} . . \mathrm{O}\left(\alpha_{\mathrm{p}}-\mathrm{sHO}^{-}\right)$distances of 1.59 and $1.16 \AA$, respectively. The relaxed potential energy surface scan after the transition state rapidly drops in energy as the deprotonated $\mathrm{iO}^{2-}$ and the $\alpha_{\mathrm{p}}-\mathrm{sOH}_{2}$ groups literally jump back to form an ideal hexagonal structure for the altered Al-honeycomb.

Another relaxed potential energy surface scan was also carried out for a proton-transfer process without a stable intermediate (Figure 7, red trace). As the proton moves from $\beta_{\mathrm{p}^{-}} \mathrm{sHO}^{-}$to an adjacent $\alpha_{\mathrm{p}}-\mathrm{sHO}^{-}$group, the corresponding $\Delta \mathrm{E}^{\mathrm{SCF}}$ value increases up to approximately 162 $\mathrm{kJ} / \mathrm{mol}$ without the presence of a local minimum. The short distance between the donor and acceptor $\mathrm{O}$ centers and the lack of stabilizing H-bonding network do not allow for the existence of a stable proton-transfer intermediate for this particular proton-transfer pathway. 


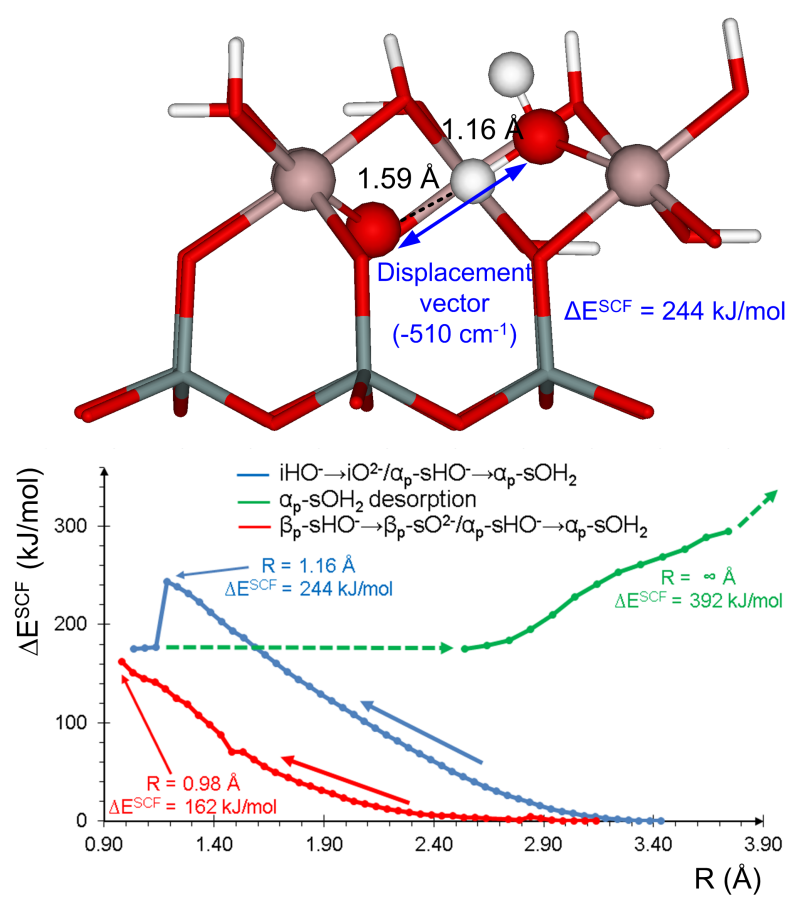

Figure 7. Relaxed (blue trace) potential energy surface scans for $\mathrm{iHO} \rightarrow \mathrm{iO}^{2-} / \alpha_{\mathrm{p}}-\mathrm{sHO} \rightarrow \alpha_{\mathrm{p}}-\mathrm{sOH}_{2}$, $\alpha_{\mathrm{p}}-\mathrm{sOH}_{2}$ water-desorption (green trace), and a non-productive proton-transfer $\beta_{\mathrm{p}}-\mathrm{sHO} \rightarrow \beta_{\mathrm{p}}-\mathrm{sO}^{2-}$ $/ \alpha_{\mathrm{p}}-\mathrm{sHO}^{-} \rightarrow \alpha_{\mathrm{p}}-\mathrm{sH}_{2} \mathrm{O}$ (red trace).

The potential energy surface of the $\alpha_{\mathrm{p}}-\mathrm{sOH}_{2}$ desorption was also mapped out that goes up to $\Delta \mathrm{E}^{\mathrm{SCF}}=392 \mathrm{~kJ} / \mathrm{mol}$ at infinite separation. As observed experimentally from TG/DTG and FTIR/ATR measurements, the desorbing water becomes trapped by the surface and goes through several H-bonded intermediates. This can be seen from the change in curvature of the light blue trace in Figure 7 at around 3.0 $\AA$. These intermediates are similar to those considered during the last step of the surface dehydration process. However, as described above for dehydration at $109 \pm 7 \mathrm{~kJ} / \mathrm{mol}$, the water will desorb from the surface under dehydroxylation conditions (temperatures above $370{ }^{\circ} \mathrm{C}$ ) let those be triggered by mechanochemical activation or contact heating. 


\section{Atomic-scale mechanism of dehydration and dehydroxylation processes}

To our knowledge, this is the first combined experimental and theoretical investigation for the mechanochemical activation of nanohalloysite toward nanometahalloysite. This process creates an activated surface with a spectrum of acidic $\left(\mathrm{Al}^{3+}\right)$ and alkaline (oxide/hydroxide) defect sites that are highly desirable for further functionalization of phylloaluminosilicate nanoparticles toward catalytic and photochemical applications. It is important to preface that mechanochemical activation, such as dry-grinding is generally considered to involve a tangled network of random chemical and physical changes. However, our modeling results indicate that there is an order in the chaos, as we can define a chain of dominant processes responsible for the compositional and structural changes under quasi-isothermal, equilibrium conditions.

The first set of processes can be assigned to dehydration of the nanoparticle surfaces $\left(\Delta \mathrm{E}^{\mathrm{SCF}}=99-118\right.$ and $45-98 \mathrm{~kJ} / \mathrm{mol}$ for $\mathrm{O}$ - and $\mathrm{T}$-sheets, respectively) followed by waterdesorption at the edges $\left(\Delta \mathrm{E}^{\mathrm{SCF}}=106-354 \mathrm{~kJ} / \mathrm{mol}\right)$. The proton-transfer processes at the edges start at $\Delta \mathrm{E}^{\mathrm{SCF}}=130 \mathrm{~kJ} / \mathrm{mol}$ and concomitant water desorption at $\Delta \mathrm{E}^{\mathrm{SCF}}=293 \mathrm{~kJ} / \mathrm{mol}$. A group of higher energy processes involves proton-transfer at the surface and water-desorption. As we have seen for the middle temperature range of TG/DTG curves in Figure 4, all processes show considerable overlap.

Using the enthalpy $\left(\Delta \mathrm{H}^{\text {corr }}\right)$ and free-energy $\left(\Delta \mathrm{G}^{\text {corr }}\right)$ correction values, the calculated electronic energies $\left(\Delta \mathrm{E}^{\mathrm{SCF}}\right)$ for each dehydroxylation step can be converted to experimentally observable values. Figure 8 compiles all possible processes for dehydration and dehydroxylation. The numerical details for generating data points in Figure 8 are shown in Table S2. Remarkably, the grouping of various processes gives a close correlation with the measured TG curves in Figure 4A at above the dehydration process of the adhesive water. Assuming an equilibrium process for each 
step, we can combine Figure 8 and the $\mathbf{G} 2$ model composition (22 e-sOH ${ }_{2}, 2$ e-sHO- 2 e-iOH 2,6 e$\mathrm{iHO}^{-}, 8$ e-aHO, $24 \mathrm{e}^{-} \mathrm{bHO}^{-}$groups at the particle periphery and $42 \mathrm{sHO}^{-}, 14 \mathrm{iHO}^{-}$at its surface from Figure 1) to define a step-wise mechanism for dehydration and dehydroxylation of the exfoliated halloysite nanoparticle. The chain of events expected to be experimentally observable in a quasi-isothermic DTG measurement when the temperature ramping schedule allows for transport phenomena and diffusion to take place completely for each measurement point.

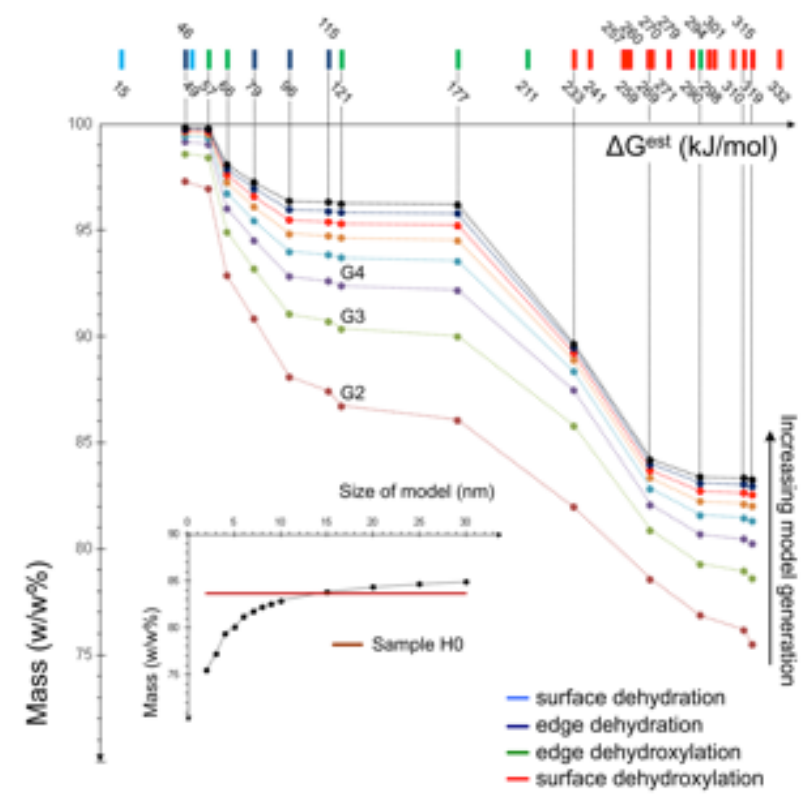

Figure 8. Estimated Gibbs free energy landscape of dehydration and dehydroxylation processes and corresponding mass loss. The inset shows the mass loss as a function of cluster model size and various dehydroxylation steps (surface dehydration steps at $\Delta \mathrm{G}^{\text {est }}=\sim 47 \mathrm{~kJ} / \mathrm{mol}$ are excluded from the mass loss calculations due to dependence of surface adsorbed water on sample history).

The mass loss upon dehydration of the surface $\left(\Delta \mathrm{G}^{\text {est }}=49 \mathrm{~kJ} / \mathrm{mol}\right)$ is ill defined due to the history of sample treatment that results in varied degrees of hydration. The first step we consider is desorption of the $22 \mathrm{e}-\mathrm{sOH}_{2}$ in $\Delta \mathrm{G}^{\text {est }}$ range of $46-115 \mathrm{~kJ} / \mathrm{mol}$ (blue bars, Figure 8). Before the completion of e- $\mathrm{iOH}_{2}$ desorption, edge dehydroxylation starts with a pair of e-aHO- next to each 
other at $\Delta \mathrm{G}^{\text {est }}=57 \mathrm{~kJ} / \mathrm{mol}$, and 6 e-bHO $\rightarrow$ e-aHO$/ \mathrm{e}-\mathrm{iHO}^{-}$at $\Delta \mathrm{G}^{\text {est }}=66 \mathrm{~kJ} / \mathrm{mol}$ (green bars, Figure 8). A characteristic energy range for dehydroxylation is represented by 2 e- $\mathrm{sHO}^{-} \rightarrow \mathrm{sHO}^{-}$and 2 $\mathrm{iHO}^{-} \rightarrow \mathrm{e}-\mathrm{bHO}^{-}$processes at $\Delta \mathrm{G}^{\text {est }}=121$ and $177 \mathrm{~kJ} / \mathrm{mol}$, respectively. As we step over the $\Delta \mathrm{G}^{\text {est }}=$ $200 \mathrm{~kJ} / \mathrm{mol}$ limit, the $\mathrm{iHO}^{-}$and $\mathrm{sHO}^{-}$groups undergo dehydroxylation. The $12 \mathrm{iHO}^{-}$groups transfer their protons to $\alpha_{\mathrm{d}^{-}} \mathrm{sHO}^{-}$at $\Delta \mathrm{G}^{\text {est }}=233 \mathrm{~kJ} / \mathrm{mol}$ through the only stable proton-transfer intermediate at $\Delta \mathrm{G}^{\text {est }}=158 \mathrm{~kJ} / \mathrm{mol}$ that likely forms already during edge dehydroxylation. The next group of dehydroxylation steps involves $10 \beta_{\mathrm{p}}-\mathrm{sHO}^{-} \rightarrow \beta_{\mathrm{d}}-\mathrm{sHO}^{-}$and 5 e-bHO ${ }^{-} \rightarrow \mathrm{e}^{-} \mathrm{bHO}^{-}$at $\Delta \mathrm{G}^{\text {est }}=269$ and $294 \mathrm{~kJ} / \mathrm{mol}$, respectively. The latter process is the highest energy step involving bridging hydroxides at the nanoparticle edges due to the energetic penalty for formation of threecoordinate $\mathrm{Si}^{4+}$ centers. The two remaining processes involving surface hydroxides are the $2 \alpha_{\mathrm{p}}{ }^{-}$ $\mathrm{sHO}^{-} \rightarrow \beta_{\mathrm{p}}-\mathrm{sHO}^{-}$and $2 \beta_{\mathrm{p}}-\mathrm{sHO}^{-} \rightarrow \beta_{\mathrm{p}}-\mathrm{sHO}^{-}$; however, these are now beyond the $\Delta \mathrm{G}^{\text {est }}=300 \mathrm{~kJ} / \mathrm{mol}$ limit (315 and $319 \mathrm{~kJ} / \mathrm{mol}$, respectively).

Figure 8 also presents the change in predicted mass loss as a function of the nanoparticle size. The details of calculations are provided in supporting information (Table S3). The simulated TG curve shows high similarity with the experimental TG curve (Figure 4) already for the G9 nanoparticle model. The calculated mass loss as a function of the nanoparticle size (see the inset in Figure 8 and Table S1) converges to a similar value for the $\mathbf{G 1 5}$ model with about $15 \mathrm{~nm}$ in diameter. This can be taken as an estimate for the effective surface area of a nanoparticle that needed to be present without major defects for dehydroxylation. It is remarkable that the theoretical predictions on the basis of molecular cluster model and the estimated mass loss upon conversion to metahalloysite particles (Figure S8) give effective nanoparticle size that agrees with the overall dimensions of particles visible in the TEM images (Figure 2B). 


\section{SUMMARY AND CONCLUSION}

The catalytic properties of clay minerals are significantly influenced by their morphology and the presence of defect sites. Thus, it is critical to understand the connection between chemical composition, primary structure, and secondary structure versus surface properties. Toward this goal we carried out investigations on exfoliated halloysite nanoscrolls with quasi-homogeneous morphology. These studies have been elusive to date. The exfoliated halloysite nanoscrolls were prepared in a four-step replacement intercalation and their surface modifications were studied as a function of the duration of dry-grinding, which is a preferred mechanochemical activation for controlled introduction of surface defects and alteration of morphology.

The porosity measurements revealed a drastic reduction of the amount of mesopores $(\sim 20 \mathrm{~nm})$ as a function of grinding time as the nanoscrolls break up and aggregate. The specific surface areas from both the BET and BJH models show similar values and similar trends. This is indicative of the presence of cylindrical shaped pores. Mechanochemical activation results in the increase of acidic sites as the $\mathrm{NH}_{3}$ surface concentration increases with increased grinding time, while the number of alkaline sites measured by $\mathrm{CO}_{2}$ adsorption remains unchanged. The slight variation of the latter can be correlated with the amphoteric behavior of surface hydroxides and presence of trapped water formed during dehydroxylation.

The thermogravimetric analysis revealed three well-defined processes for dehydration and dehydroxylation. These were assigned to desorption of the surface adsorbed water $\left(\mathrm{T}=20-183 \pm 18{ }^{\circ} \mathrm{C}\right)$, highly overlapping dehydration and dehydroxylation processes $\left(\mathrm{T}=183 \pm 18-369 \pm 10{ }^{\circ} \mathrm{C}\right)$, surface dehydroxylation $\left(\mathrm{T}=369 \pm 10{ }^{\circ} \mathrm{C}-600{ }^{\circ} \mathrm{C}\right)$ with peak maxima in the range of $453-472{ }^{\circ} \mathrm{C}$. Mechanochemical activation reduces the height of the surface dehydroxylation step, while increases the amount of adhesive water. An important conclusion of 
the thermal analysis is that a cleaned surface cannot be produced by heat-treatment without undergoing structural and compositional changes, since the dehydration and dehydroxylation steps strongly overlap.

FTIR measurements further corroborate the observations from porosity and thermal analysis since the characteristic $\mathrm{OH}$ stretching $\left(3700-3600 \mathrm{~cm}^{-1}\right), \mathrm{O} / \mathrm{Si} / \mathrm{O}\left(1044-1035,1008-1000 \mathrm{~cm}^{-1}\right)$, $\mathrm{Al} / \mathrm{O} / \mathrm{Si}\left(537-520 \mathrm{~cm}^{-1}\right)$, and $\mathrm{OH}$ deformation $\left(930-800 \mathrm{~cm}^{-1}\right)$ bands shifts and their intensities change. Particularly, the intensities of inner hydroxide stretching band $\left(3620 \mathrm{~cm}^{-1}\right)$ decrease with the increase of the grinding time. This is of great importance since this characteristic band often used as an internal reference. The spectral changes indicate that upon contact heating or mechanochemical activation, the nanoparticle undergo simultaneous dehydroxylation and hydration. Dry-grinding generates surface temperatures where dehydration, proton-transfer, and dehydroxylation can take place spontaneously.

A comprehensive mapping of the potential energy surface for 23 dehydration and 22 dehydroxylation pathways were carried out using molecular cluster models for the nanoparticle and previously validated density functional theory. The energetically most favorable pathways were used to define atomic-scale mechanism for water-desorption and proton-transfer. The latter converts two adjacent hydroxide groups to an oxide group and a bound water. A theoretical thermogravimetric curve constructed on the basis of this large dataset shows a good agreement with experiments. We found that an effective molecular cluster size of at least $15 \mathrm{~nm}$ in diameter can describe the observed mass losses due to dehydration and dehydroxylation. This is the characteristic dimension of exfoliated nanoscrolls from TEM images. Overall, the combined experimental work and computational modeling provided valuable insights into the effects of mechanochemical modification of the morphology, surface structure, and composition. This 
knowledge is a key for the rationalized preparation of halloysite-based nanocomposites and nanohybrids.

\section{ACKNOWLEDGEMENT}

The financial supports of the GINOP-2.3.2-15-2016-00016 and GINOP-2.3.2-15-2016-00053 projects (co-financed by Széchenyi 2020 program) and the HI-LED EU FP7 project (grant No. 619912) are acknowledged. Computational resources from the Hyalite High Performance Computational Center at Montana State University are greatly appreciated. R.K.Sz. and A.T. were supported by the MTA-ELTE Chemical Structure \& Function "Momentum" Laboratory (ID 96122) by the Hungarian Academy of Sciences, Budapest, Hungary (Contract No. LP201510/2015).

Supporting Information: N2 adsorption-desorption vs. grinding time; resolved DTG curves; comparison of FTIR/ATR spectra; molecular cluster models and relative energies for all dehydration, proton-transfer, and dehydroxylation steps; predicted molecular structure of nanometakaolinite; summary of all estimated enthalpies and Gibbs free energies; numberical details of theoretical mass loss curves. All atomic positional coordinates are depositive in Montana State University Scholarworks, digital data repository at https://doi.org/10.15788/M25P4S. 


\section{REFERENCES}

1. Yuan, P.; Tan, D.; Annabi-Bergaya, F. Properties and Applications of Halloysite Nanotubes: Recent Research Advances and Future Prospects. Appl. Clay Sci. 2015, 112 113, 75-93.

2. Joussein, E.; Petit, S.; Churchman, J.; Theng, B.; Righi, D.; Delvaux, B. Halloysite clay minerals - A review. Clay Minerals 2005, 40, 383-426.

3. Chiu, C.-W.; Huang, T.-K.; Wang, Y.-C.; Alamani, B. G.; Lin, J.-J. Intercalation Strategies in Clay/polymer Hybrids. Prog. Polym. Sci. 2014, 39, 443-485.

4. Zsirka, B.; Horváth, E.; Szabó, P.; Juzsakova, T.; Szilágyi, R. K.; Fertig, D.; Makó, É.; Varga, T.; Kónya, Z.; Kukovecz, Á.; Kristóf, J. Thin-walled Nanoscrolls from Multi-step Intercalation from Tubular Halloysite-10 and its Rearrangement upon Peroxide Treatment. Appl. Surf. Sci. 2017, 399, 245-254.

5. Kuroda, Y.; Ito, K.; Itabashi, K.; Kuroda, K. One-Step Exfoliation of Kaolinites and Their Transformation into Nanoscrolls. Langmuir 2011, 27, 2028-2035.

6. Letaief, S.; Detelleir, C. Clay-Polymer Nanocomposite Material from the Delamination of Kaolinite in the Presence of Sodium Polyacrylate. Langmuir 2009, 25, 10975-10979.

7. Matusik, J.; Gaweł, A.; Bielańska, E.; Osuch, W.; Bahranowski, K. The Effect of Structural Order on Nanotubes Derived from Kaolin-Group Minerals. Clays Clay Miner 2009, 57, 452-464.

8. Gardolinski, J. E. F. C.; Lagaly, G. Grafted organic derivatives of kaolinite: I. Synthesis, chemical and rheological characterization. Clay Minerals 2005, 40, 537-546.

9. Matusik, J.; Gawel, A.; Bahranowski, K., Grafting of methanol in dickite and intercalation of hexylamine. Appl. Clay Sci. 2012, 56, 63-67.

10. Gardolinski, J. E. F. C.; Lagaly, G., Grafted organic derivatives of kaolinite: II. Intercalation of primary n-alkylamines and delamination. Clay Minerals 2005, 40, 547-556.

11. Lagaly, G.; Barrer, R. M.; Goulding, K. Clay Minerals: Their Structure, Behaviour and Use. In Phil. Trans. Royal Soc. London. Series A, Math. Phys. Sci., The Royal Society London, U.K., 1984; Vol. 311, pp 315-332.

12. Li, X.; Liu, Q.; Cheng, H.; Zhang, S.; Frost, R. L. Mechanism of Kaolinite Sheets Curling via the Intercalation and Delamination Process. J. Colloid Interface Sci 2015, 444, 74-80. 
13. Criscenti, L. J.; Brantley, S. L.; Mueller, K. T.; Tsomaia, N.; Kubicki, J. D. Theoretical and ${ }^{27}$ Al CPMAS NMR Investigation of Aluminum Coordination Changes during Aluminosilicate Dissolution. Geochim. Cosmochim. Acta 2005, 69, 2205-2220.

14. Táborosi, A.; Szilagyi, R. K. Realistic Molecular Cluster Models for Exfoliated Kaolinite. Clay Minerals 2015, 50, 308-331.

15. Táborosi, A.; Kurdi, R.; Szilágyi, R. K. The positions of inner hydroxide groups and aluminium ions in exfoliated kaolinite as indicators of the external chemical environment. Physical Chemistry Chemical Physics 2014, 16, 25830-25839.

16. Matusik, J.; Scholtzova, E.; Tunega, D. Influence of Synthesis Conditions on the Formation of a Kaolinite-Methanol Complex and Simulation of its Vibrational Spectra. Clays and Clay Minerals 2012, 60, 227-239.

17. Szabó, P.; Zsirka, B.; Fertig, D.; Horváth, E.; Csizmadia, T.; Kristóf, J. Delaminated Kaolinites as Potential Photocatalysts: Tracking Degradation of Na-Benzenesulfonate Test Compound Adsorbed on the Dry Surface of Kaolinite Nanostructures. Catal. Today 2017, in press, 10.1016/j.cattod.2017.01.051.

18. Zsirka, B.; Horváth, E.; Makó, É.; Kurdi, R.; Kristóf, J. Preparation and Characterization of Kaolinite Nanostructures: Reaction Pathways, Morphology and Structural Order. Clay Minerals 2015, 2015, 329-340.

19. Makó, É.; Kovács, A.; Horváth, E.; Kristóf, J. Kaolinite-Potassium Acetate and HalloysitePotasium Acetate Complexes Prepared by Mechanochemical, Solution and Homogenization Techniques: A Comparative Study Clay Miner. 2014, 49, 457-471.

20. Brunauer, S.; Emmett, P. H.; Teller, E. Adsorption of Gases in Multimolecular Layers. $J$. Am. Chem. Soc. 1938, 60, 309-319.

21. Barrett, E. P.; Joyner, L. G.; Halenda, P. P. The Determination of Pore Volume and Area Distributions in Porous Substances. I. Computations from Nitrogen Isotherms. J. Am. Chem. Soc. 1951, 73, 373-380.

22. White, G. N., Zelazny, L. W. Analysis and Implications of the Edge Structure of Dioctahedral Phyllosilicates. Clays Clay Miner. 1988, 36, 141-146.

23. Liu, X. D.; Lu, X. C.; Wang, R. C.; Meijer, E. J.; Zhou, H. Q.; He, H. P., Atomic Scale Structures of Interfaces between Kaolinite Edges and Water. Geochimica Et Cosmochimica Acta 2012, 92, 233-242. 
24. Perdew, J. P.; Chevary, J. A.; Vosko, S. H.; Jackson, K. A.; Pederson, M. R.; Singh, D. J.; Fiolhais, C. Atoms, Molecules, Solids, and Surfaces - Applications of the Generalized Gradient Approximation for Exchange and Correlation. Phys. Rev. B 1992, 46, 6671-6687.

25. Perdew, J. P.; Wang, Y. Accurate and Simple Analytic Representation of the Electron-Gas Correlation-Energy. Phys. Rev. B 1992, 45, 13244-13249.

26. Grimme, S.; Antony, J.; Ehrlich, S.; Krieg, H. A Consistent and Accurate Ab Initio Parametrization of Density Functional Dispersion Correction (DFT-D) for the 94 Elements H-Pu. J. Chem. Phys. 2010, 132, 154104.

27. Schäfer, A.; Horn, H.; Ahlrichs, R. Fully Optimized Contracted Gaussian Basis Sets for Atoms Li to Kr. J. Chem. Phys. 1992, 97, 2571-2577.

28. Schäfer, A.; Huber, C.; Ahlrichs, R. Fully Optimized Contracted Gaussian Basis Sets of Triple Zeta Valence Quality for Atoms Li to Kr. J. Chem. Phys. 1994, 100, 5829-5835.

29. Tomasi, J.; Mennucci, B.; Cammi, R. Quantum Mechanical Continuum Solvation Models. Chem. Rev. 2005, 105, 2999-3093.

30. Frisch, M. J.; Trucks, G. W.; Schlegel, H. B.; Scuseria, G. E.; Robb, M. A.; Cheeseman, J. R.; Scalmani, G.; Barone, V.; Mennucci, B.; Petersson, G. A.; Nakatsuji, H.; Caricato, M.; Li, X.; Hratchian, H. P.; Izmaylov, A. F.; Bloino, J.; Zheng, G.; Sonnenberg, J. L.; Hada, M.; Ehara, M.; Toyota, K.; Fukuda, R.; Hasegawa, J.; Ishida, M.; Nakajima, T.; Honda, Y.; Kitao, O.; Nakai, H.; Vreven, T.; Montgomery, J. A., Jr.; Peralta, J. E.; Ogliaro, F.; Bearpark, M.; Heyd, J. J.; Brothers, E.; Kudin, K. N.; Staroverov, V. N.; Kobayashi, R.; Normand, J.; Raghavachari, K.; Rendell, A.; Burant, J. C.; Iyengar, S. S.; Tomasi, J.; Cossi, M.; Rega, N.; Millam, N. J.; Klene, M.; Knox, J. E.; Cross, J. B.; Bakken, V.; Adamo, C.; Jaramillo, J.; Gomperts, R.; Stratmann, R. E.; Yazyev, O.; Austin, A. J.; Cammi, R.; Pomelli, C.; Ochterski, J. W.; Martin, R. L.; Morokuma, K.; Zakrzewski, V. G.; Voth, G. A.; Salvador, P.; Dannenberg, J. J.; Dapprich, S.; Daniels, A. D.; Farkas, Ö.; Foresman, J. B.; Ortiz, J. V.; Cioslowski, J.; Fox, D. J. Gaussian 09, Revision C.01; Gaussian, Inc.: Wallingford CT, 2009.

31. Adrienko, G. A. Chemcraft Version 1.8 (build 489) visualizer and molecule editor program, http://www.chemcraftprog.com: 2016.

32. Accelrys Digital Studio Viewer Pro version 5.0 visualizer and molecule editor program, http://www.accelrys.com: 2002. 
33. Groen, J. C.; Peffer, L. A. A.; Perez-Ramiez, J. Pore Size Determination in Modified Micro- and Mesoporous Materials. Pitfalls and Limitations in Gas Adsorption Data Analysis. Microporous Mesoporous Mater 2003, 60, 1-17.

34. Vágvölgyi, V.; Kovács, J.; Horváth, E.; Kristóf, J.; Makó, É. Investigation of Mechanochemically Modified Kaolinite Surfaces by Thermoanalytical and Spectroscopic Methods. J. Colloid Interface Sci. 2008, 317, 523-529.

35. Knözinger, H.; Ratnasamy, P. Catalytic Aluminas: Surface Models and Characterization of Surface Sites. Catal. Rev. 1978, 17, 31-70.

36. Sohlberg, K.; Pennycook, S. J.; Pantelides, S. T. The Bulk and Surface Structure of $\gamma$ Alumina. Chem. Eng. Commun. 2000, 181, 107-135.

37. Parkyns, N. D. The Surface Properties of Metal Oxides. Part II. An Infrared Study of the Adsorption of Carbon Dioxide on $\gamma$-Alumina. J. Chem. Soc. A (Inorg. Phys. Theor.) 1969, $410-417$.

38. Horváth, E.; Frost, R. L.; Makó, É.; Kristóf, J.; Cseh, T. Thermal Treatment of Mechanochemically Activated Kaolinite. Thermochim. Acta 2003, 404, 227-234.

39. Farmer, V. C. The Infrared Spectra of Minerals. Mineralogical Society: London, Department; 1974, Vol. 15.

40. Cheng, H. F.; Frost, R. L.; Yang, J.; Liu, Q. F.; He, J. K. Infrared and Infrared Emission Spectroscopic Study of Typical Chinese Kaolinite and Halloysite. Spectrochim. Acta Part A-Mol. Biomol. Spectr. 2010, 77, 1014-1020.

41. Horváth, E.; Kristóf, J.; Frost, R. L. Vibrational Spectroscopy of Intercalated Kaolinites. Part I. App. Spectr. Rev. 2010, 45, 130-147.

42. Frost, R. L. Hydroxyl Deformation in Kaolins. Clays and Clay Minerals 1998, 46(3), 280-289.

43. Taborosi, A.; Szilagyi, R. K. Behaviour of Surface Hydroxide Groups of Exfoliated Kaolinite in Gas Phase and during Water Adsorption. Dalton Trans. 2016, 45, 2523-2535.

44. Hu, X. L.; Michaelides, A. Water on the Hydroxylated (001) Surface of Kaolinite: From Monomer Adsorption to a flat 2D Wetting Layer. Surface Science 2008, 602(4), 960-974.

45. Solc, R.; Gerzabek, M. H.; Lischka, H.; Tunega, D. Wettability of Kaolinite (001) Surfaces - Molecular Dynamic Study. Geoderma 2011, 169, 47-54. 